\author{
Universidade de São Paulo \\ Faculdade de Filosofia, Ciências e Letras de Ribeirão Preto \\ Departamento de Psicologia e Educação
}

Mikael Cavallet

\title{
Um estudo sobre a distribuição da atenção pelo campo visual usando o Julgamento de Ordem Temporal (JOT)
}

Ribeirão Preto 



$$
\text { Universidade de São Paulo }
$$

Faculdade de Filosofia, Ciências e Letras de Ribeirão Preto

Departamento de Psicologia e Educação

Mikael Cavallet

\title{
Um estudo sobre a distribuição da atenção pelo campo visual usando o Julgamento de Ordem Temporal (JOT)
}

\author{
Dissertação apresentada à Faculdade \\ de Filosofia, Ciências e Letras de Ribeirão \\ Preto da Universidade de São Paulo, como \\ parte das exigências para a obtenção do \\ Título de Mestre em Ciências - Área de \\ concentração: Psicobiologia
}

Orientador: Prof. Dr. César Galera

Ribeirão Preto 
Autorizo a reprodução e divulgação total ou parcial deste trabalho, por qualquer meio convencional ou eletrônico, para fins de estudo e pesquisa, desde que citada a fonte.

\section{FICHA CATALOGRÁFICA}

Cavallet, Mikael

Um estudo sobre a distribuição da atenção pelo campo visual usando o Julgamento de Ordem Temporal (JOT).

Ribeirão Preto-SP-2006

86 p.: fig.

Dissertação de Mestrado, apresentada à Faculdade de Filosofia, Ciências e Letras de Ribeirão/USP - Área de concentração: Psicobiologia

Orientador: Galera, César

1. Atenção Visual 2. Foco Atentivo, 3. Forma, 4. Tarefa de Julgamento de Ordem Temporal (JOT). 
Dedico este trabalho aos meus pais, Rita e Luiz Carlos. 



\section{Agradecimentos}

Agradeço em especial ao Professor Doutor César Galera pela paciência e oportunidades que me ofereceu durante o mestrado. Obrigado pela convivência amiga desde os primeiros dias de estágio no laboratório.

Aos meus pais, Rita e Luiz Carlos Cavallet pela educação, amor e incentivo aos estudos.

A Angelita Stabile, pessoa a qual tenho grande respeito e amor. Companheira para a vida toda.

Aos amigos: Douglas, Eduardo, Vitor, Leonardo, Anderson, Leandro, Adriana e Edilaine, pelos momentos de descontração e apoio.

Aos atuais e ex-companheiros de laboratório: Carlo Rondinoni, Joaquim Rossini, Marina Caprio e Veridiana Nogueira pelas dicas importantes e pelas boas conversas. Ao Guilherme, Eduardo, Gabriel e Marcelo pelo coleguismo.

Ao Igor, pela alegria, dedicação e apoio técnico.

A Renata, pelas informações úteis.

A Cidinha e a Sueli pelo fornecimento de cafeína.

Aos participantes dos experimentos que cederam parte do seu tempo e "atenção visual", sem os quais não seria possível a realização deste estudo.

A USP e a FFCLRP, pela oportunidade de realização do curso de mestrado.

A CAPES pela concessão da bolsa de mestrado e pelo apoio financeiro para a realização desta pesquisa.

A todos àqueles que de alguma forma me ajudaram e esqueci de citar, desculpe a falha. 



\section{Sumário}

Resumo

Abstract

Introdução

Distribuição dos Recursos Atentivos 4

Seleção da Informação Visual 6

A Forma do Foco Atentivo 11

A Tarefa de Julgamento de Ordem Temporal 15

$\begin{array}{ll}\text { Experimentos } & 19\end{array}$

2.1 Experimento $1 \mathrm{~A}$ - Percepção de ordem temporal dentro e fora de $\begin{array}{ll}\text { uma moldura } & 21\end{array}$

$\begin{array}{ll}\text { Método } & 22\end{array}$

Participantes $\quad 22$

Material e Estímulos $\quad 22$

Procedimento 24

Análise $\quad 26$

$\begin{array}{ll}\text { Resultados } & 27\end{array}$

$\begin{array}{ll}\text { Discussão } & 28\end{array}$

2.2 Experimento 1B - Viés de resposta e Distribuição dos recursos atentivos 31

Método 32

Participantes 32

Material e Estímulos 32

Procedimento 33

Análise $\quad 35$

Resultados $\quad 36$

$\begin{array}{ll}\text { Discussão } & 39\end{array}$

2.3 Experimento 2 - Gradiente de distribuição espacial da atenção 43

Método 46

$\begin{array}{ll}\text { Participantes } & 46\end{array}$

Material e Estímulos $\quad 46$ 

$\begin{array}{ll}\text { Procedimento } & 47\end{array}$

Análise $\quad 48$

$\begin{array}{ll}\text { Resultados } & 48\end{array}$

Discussão $\quad 50$

2.4 Experimento 3 - Dinâmica temporal da atenção visual 52

Método 53

$\begin{array}{ll}\text { Participantes } & 53\end{array}$

Material e Estímulos 53

Procedimento 54

Análise $\quad 55$

$\begin{array}{ll}\text { Resultados } & 55\end{array}$

Discussão $\quad 58$

Discussão Geral $\quad 62$

$\begin{array}{ll}\text { Referências Bibliográficas } & 71\end{array}$

$\begin{array}{ll}\text { Anexos } & 77\end{array}$ 



\section{Resumo}

\section{CAVALLET, M. Um estudo sobre a distribuição da atenção pelo campo visual usando o julgamento de ordem temporal (JOT). 2006. 86 p. Dissertação de Mestrado - Faculdade de Filosofia, Ciências e Letras de Ribeirão Preto, Universidade de São Paulo, Ribeirão Preto.}

Nós realizamos três experimentos para estudar a distribuição da atenção pelo campo visual e a possibilidade dos recursos atentivos serem mais concentrados no interior de uma área delimitada por uma figura geométrica de aparecimento abrupto. Os participantes realizaram uma tarefa de julgamento de ordem temporal (JOT), na qual julgaram a ordem de duas letras apresentadas em seqüência. Uma letra foi apresentada dentro e a outra fora de uma moldura, que não foi relacionada com a tarefa. A percepção de ordem temporal foi influenciada pela moldura nos três experimentos. A variação da distância entre as duas letras e o tempo de exposição da moldura foram manipulados, alterando o julgamento dos participantes. Os resultados demonstraram uma variação na concentração dos recursos atentivos em função da distância entre as duas letras e em função do tempo de exposição da moldura. Os resultados sugerem que a forma de uma figura geométrica pode produzir uma reorganização dos recursos atentivos, que parecem estar mais concentrados dentro do que fora das suas bordas.

Palavras-Chave: Atenção visual, foco atentivo, forma, tarefa de julgamento de ordem temporal (JOT). 



\begin{abstract}
CAVALLET, M. The distribution of visual attention: evidence based on temporal order judgment (TOJ) task. 2006. 86 p. Dissertação de Mestrado - Faculdade de Filosofia, Ciências e Letras de Ribeirão Preto, Universidade de São Paulo, Ribeirão Preto.
\end{abstract}

We conducted three experiments to examine the distribution of visual attention and the possibility of the attentional resources to be concentrated along an area delimited by a frame of abrupt onset. The participants performed a temporal order judgment (TOJ) task, in which judged the order of two letters presented in sequence. One letter was showed inside and other outside a frame that was not related to the task. Perception of temporal order was influenced by the frame in all experimental conditions. The judgement of participants was affected by the distance between the two letters and the cue lead time. The findings suggest that the form of a geometric figure can reallocate the resources of attention that should be more concentrated inside than outside of its borders.

Key-words: Visual attention, attentional focus, shape, judgment of temporal order (TOJ) task. 
1. INTRODUÇÃO 
O reconhecimento dos eventos que acontecem em uma cena tem um papel adaptativo importante do sistema visual em nossas atividades diárias. Vários objetos de tamanhos e formas diferentes compõem o ambiente ao nosso redor e cada um pode ser alvo da nossa ação. No entanto, o sistema visual é limitado quanto à quantidade de informação que pode ser processada simultaneamente. Esse limite sugere que em algum estágio do fluxo de informação, ocorre uma seleção ou priorização dos eventos que continuarão sendo processados.

Nos últimos cinqüenta anos, vários estudos têm se dedicado a essa questão, demonstrando que a atenção pode atuar na seleção dos estímulos, aumentando o processamento de estímulos atendidos em relação a eventos que não recebem atenção e/ou suprimindo o processamento de outros estímulos (BROADBENT, 1958; ERIKSEN; ST. JAMES, 1986; POSNER, 1980).

Estudos utilizando tarefas que informam ao observador o local onde um alvo será apresentado têm fornecido parte desse conhecimento sobre os mecanismos atentivos envolvidos no processamento da informação visual. Esse tipo de procedimento é usado para investigar como os recursos atentivos são distribuídos entre regiões ou objetos, quando estímulos visuais diferentes competem pela atenção (ERIKSEN; YEH, 1985; POSNER; SNYDER; DAVIDSON, 1980).

A seguir, descreveremos como a atenção visual pode ser distribuída pelo campo visual e os principais fatores relacionados ao nosso trabalho que podem interferir nessa distribuição da atenção. As outras seções seguirão com a descrição da seleção da informação visual espacial e a possibilidade dos recursos serem destinados a figuras geométricas com áreas bem delimitadas. Por último, apresentaremos a tarefa utilizada neste estudo. 


\subsection{Distribuição dos Recursos Atentivos}

A atenção pode ser distribuída pelo campo visual de duas maneiras, uma difusa e outra focalizada. No modo difuso, os recursos do sistema atentivo podem ser espalhados igualmente por todo o cenário com um processamento rápido e paralelo dos eventos. Em outras circunstâncias, quando as características da tarefa exigem um nível alto de processamento da informação, os recursos disponíveis são focalizados e todos os estímulos selecionados são analisados serialmente, caracterizando um processamento mais seletivo e concentrado da atenção visual (ERIKSEN; ST. JAMES, 1986; JONIDES, 1983; POSNER; SNYDER; DAVIDSON, 1980).

A focalização da atenção para o local ou objeto a ser processado depende fundamentalmente das propriedades da imagem, isto é, das características dos estímulos que compõe o cenário e dos objetivos e necessidades do observador. Assim, dois processos de ativação da atenção são sugeridos: ativação bottom-up e ativação top-down, também chamadas, respectivamente, de dirigida pelo estímulo (stimulus-driven) e direcionada pelo objetivo do observador (goal-directed). Posner (1980) caracterizou a ativação bottom-up como exógena, termo utilizado pelo autor por referir-se a um conceito neurológico de reflexo, e Yantis e Jonides (1984) utilizaram o termo automático. Ambos sugerem uma orientação reflexa e involuntária da atenção em resposta a uma característica do estímulo, como por exemplo, uma mudança de luminosidade de qualquer estímulo na periferia do campo visual. Já o modo top-down envolve a orientação endógena, voluntária, controlada da atenção, regida pelas estratégias do observador, que dependem da sua motivação e da interpretação de informações simbólicas, como por exemplo, dicas centrais, que 
sugerem o local ao qual o observador deve direcionar a sua atenção (POSNER, 1980).

A reorganização automática dos recursos atentivos tem sido muito explorada nos últimos anos. Em parte isso se deve a comparação direta entre a manipulação de características específicas dos estímulos visuais e os efeitos obtidos com essas mudanças. Outro motivo é a menor influência de aspectos motivacionais e internos do observador, que devem estar mais presentes na modulação atentiva voluntária do que na ativação reflexa da atenção (PASHLER; JOHNSTON; RUTHRUFF, 2001; YANTIS; JONIDES, 1990).

A utilização de propriedades específicas dos estímulos como àquelas que, diferem substancialmente em um ou mais atributos visuais dos estímulos que compõe o cenário (por exemplo, movimento, cor e orientação), assim como as características que ocorrem em um intervalo de tempo muito curto (aparecimento abrupto de um objeto), têm permitido aos pesquisadores controlar a reorganização automática da atenção (EGETH; YANTIS, 1997). Posner (1980) utilizou um estímulo apresentado rapidamente na periferia do campo visual (uma moldura), para indicar o local em que um alvo seria apresentado, e verificou tempos de respostas (RT) rápidos, quando o alvo foi apresentado subsequentemente no mesmo local dessa dica periférica. Yantis e Jonides (1984) verificaram que o tempo necessário para um observador realizar uma tarefa de busca, diminuía com a apresentação de alvos de início abrupto e aumentava quando estímulos com características semelhantes ao do alvo (flankers) eram apresentados da mesma forma, próximos ao alvo. Yantis e Jonides concluíram que o aparecimento súbito do estímulo no campo visual provavelmente capturou a atenção, pois quando o alvo era apresentado de forma abrupta, a resposta era realizada imediatamente e o observador não precisava 
continuar a busca pelo alvo, mas se os estímulos apresentados de maneira abrupta não eram o alvo, os recursos atentivos deveriam ser redistribuídos para que a tarefa fosse concluída. Eles sugeriram que dicas periféricas, como aquelas usadas por Posner (1980) capturaram a atenção por que eram estímulos de início abrupto, assim como, os utilizados em seus experimentos. Remington, Johnston e Yantis (1992) forneceram outras evidências, demonstrando que uma dica periférica pode reorganizar os recursos da atenção mesmo quando os observadores sabem que ela nunca indicará o local do alvo.

Outro fator importante na determinação do tipo de ativação dos recursos atentivos é o intervalo de tempo fornecido ao sistema visual para processar a informação. Os dois tipos de ativação parecem possuir modulações características quanto ao intervalo de tempo entre o início da apresentação de dois estímulos (stimuli onset asynchrony - SOA). Os resultados mostram que a distribuição voluntária da atenção está associada a períodos de tempo mais longos, acima de 400ms, enquanto o deslocamento automático, aumenta rapidamente por volta de 100ms após a apresentação de dicas periféricas, diminuindo em seguida, caso o observador não tenha incentivo para manter a atenção no local indicado (CHEAL; LYON, 1991; MÜLLER; RABBITT, 1989; NAKAYAMA; MACKEBEN, 1989). Esses resultados sugerem que a linha de tempo da facilitação proporcionada pela atenção, compreende uma fase inicial transitória, seguida por um componente voluntário, que pode se estender por mais tempo.

\subsection{Seleção da Informação Visual}

Uma definição muito aceita e conhecida de atenção visual é a da atenção como um foco de processamento da informação. De acordo com essa idéia, a 
atenção pode se deslocar de um ponto a outro do campo visual como o foco de uma lanterna (spotlight), ocupando uma única região do espaço (POSNER, 1980; POSNER; SNYDER; DAVIDSON, 1980). Estímulos visuais abrangidos por esse foco atentivo são detectados com maior facilidade, excluindo a informação fora dessa região. No paradigma clássico de Posner et al. (1980) os participantes foram instruídos a fixar o olhar em um ponto no centro da tela e uma dica (quadrado) foi brevemente apresentada em um dos lados do campo visual, informando ao observador o local onde o alvo poderia aparecer. Quando o alvo foi apresentado no local indicado, o tempo de reação dos participantes foi mais rápido do que na condição em que a dica informava incorretamente a localização do alvo. A diferença na velocidade de processamento dos estímulos apresentados dentro do quadrado levou a conclusão de que os mecanismos atentivos não podem ser distribuídos livremente pelo campo visual, do contrário, o local indicado não interferiria na velocidade do tempo de reação.

Resultados semelhantes foram obtidos por Zimba e Hughes (1987), que apresentaram dez quadrados demarcando possíveis localizações onde um alvo seria apresentado. Eles verificaram que o tempo de reação dos observadores aumentava rapidamente com o aumento da distância entre o quadrado indicado e a localização em que o alvo era apresentado. Esse efeito sugere que os observadores podem ter focalizado a sua atenção para a pequena região dentro do quadrado indicado.

De acordo com os estudos de Posner et al. (1980), a informação apresentada em regiões não indicadas leva a um movimento do foco atentivo para o local em que esta informação é apresentada, aumentando o tempo de processamento dessa informação. O movimento do foco presumivelmente leva tempo, e os RTs mais 
lentos nos locais não indicados são atribuídos ao tempo que o foco atentivo leva para percorrer a distância entre o local indicado e a informação relevante para a tarefa.

LaBerge (1983) adicionou ao modelo da lanterna, evidências de que esse foco da atenção poderia ser mais flexível em relação ao tamanho e a seleção da informação localizada fora do foco. Seus resultados sugeriram a capacidade do foco se concentrar em uma extensão menor do que $0,3^{\circ}$ de ângulo visual e expandir para uma área de aproximadamente $2,0^{\circ}$. LaBerge e Brown (1989) mostraram que a distribuição da atenção fora da região de maior concentração de recursos atentivos pode diminuir gradualmente conforme o aumento da distância entre o centro de ativação (dica) e o estímulo apresentado fora desse ponto inicial.

Evidências adicionais do ajustamento da atenção ao tamanho de uma região selecionada foram mostradas por Eriksen e St. James, (1986), que sugeriram uma metáfora um pouco diferente àquela da lanterna. A metáfora proposta foi a do funcionamento da atenção como o zum de uma lente, no qual a eficiência do processamento dentro da área abrangida pelo foco deve ser inversamente proporcional ao seu tamanho, um efeito conhecido como o "efeito do tamanho da dica" (ERIKSEN; ST. JAMES, 1986; ERIKSEN; YEH, 1985). Esse efeito é considerado como uma evidência do ajustamento do foco da atenção ao tamanho da região selecionada.

Castiello e Umiltá (1990) também encontraram um efeito do tamanho da dica usando, no primeiro experimento do seu estudo, uma dica similar àquela usada por Posner et al. (1980). O tamanho do quadrado apresentado como dica foi manipulado e o intervalo entre dica e alvo (SOA) foi de 40 ou $500 \mathrm{~ms}$. O efeito do tamanho da dica só ocorreu para o intervalo de tempo maior, sugerindo que o ajustamento do 
foco da atenção ao tamanho da região indicada necessita de certo tempo para ocorrer. Um benefício no TR foi encontrado no intervalo mais curto, independente do tamanho da moldura, indicando que em um intervalo de tempo muito curto, apenas o processo de orientação da atenção deve ocorrer para o local indicado.

A primeira tentativa de estudar a orientação separada do processo de focalização foi realizada por Maringelli e Umiltà (1998). Eles apresentaram a dica (quadrado) e o alvo sempre em uma mesma posição no centro da tela e encontraram o efeito do tamanho da dica com um SOA de 100ms. Turatto, Benso, Facoetti, Galfano, Mascetti e Umiltà (2000) demonstraram que o processo de focalização pode ser automático e parece ocorrer apenas na presença do objeto, que deve funcionar como suporte a atenção, provavelmente devido à impossibilidade do ajuste ocorrer em uma região vazia do espaço. Outras evidências a favor do ajuste automático do foco atentivo também foram apresentadas por Benso, Turatto, Mascetti e Umiltà (1998).

Apesar de vários trabalhos demonstrarem a importância da localização espacial no processo de seleção, muitos estudos têm sugerido que a seleção da informação visual pode ser realizada independente do local ocupado por esses eventos no campo visual (BAYLIS; DRIVER, 1993; DUNCAN, 1984; GIBSON, 1994; KAHNEMAN; TREISMAN; GIBBS, 1992; KRAMER; JACOBSON, 1991). De acordo com esses estudos, o processo de focalização pode ocorrer baseado apenas nas características dos objetos ou grupos de objetos. O sistema visual seria forte 0 bastante para classificar ou identificar muitos objetos visuais rapidamente e em paralelo, num estágio pré-atentivo. A seleção ocorreria em um estágio posterior, onde as características do objeto selecionado seriam analisadas mais detalhadamente. Assim, segundo esses modelos, as molduras utilizadas nos 
trabalhos de Posner et al. (1980) e Zimba e Hughes (1987) poderiam ter sido selecionadas como objetos e não como posições espaciais delimitadas.

Outros trabalhos têm considerado a possibilidade da atenção atuar sobre a seleção dos estímulos de maneira combinada, levando em conta tanto a posição espacial como o objeto que se encontra nessa posição (BROWN; BREITMEYER; LEIGHTY; DENNEY, 2006; KRAMER; JACOBSON, 1991). Egly, Driver e Rafal (1994) examinaram os componentes da atenção espacial e do objeto em pacientes com um dos lobos parietais lesionado. Verificaram que lesões no lado direito prejudicavam apenas componentes espaciais, enquanto lesões no lado esquerdo prejudicavam tanto componentes espaciais quanto componentes de seleção baseados no objeto, sugerindo que cada hemisfério pode ser diferentemente especializado no processamento de cada componente da atenção visual. Vecera e Farah (1994) observaram que quando a tarefa solicitada ao participante não envolve o acesso as formas dos objetos, mas requerem apenas a detecção de um pequeno ponto apresentado em várias localizações sobre os contornos dos objetos, apenas efeitos espaciais são encontrados. Eles atribuíram à atenção espacial a capacidade de poder se adaptar a forma de um objeto selecionando a sua localização espacial exata. Lavie e Driver (1996) verificaram que os efeitos tipicamente encontrados em uma seleção baseada no objeto desapareciam quando os seus participantes foram instruídos a atender a uma determinada localização espacial. Segundo os autores, os resultados demonstram que a seleção pode ocorrer dentro do espaço sendo influenciada pelas características do objeto. 


\subsection{A Forma do Foco Atentivo}

Uma possibilidade investigada pelos modelos de distribuição espacial da atenção é a de que o foco da atenção possa ser moldado à forma dos objetos. Como o sistema visual recebe uma grande quantidade de informação, sendo que nem toda informação é completamente processada, e dada a importância da localização espacial na seleção dos estímulos, alguns estudos têm considerado a forma dos objetos localizados no campo visual como uma das muitas características às quais o foco da atenção pode ser sensível.

Egly e Homa (1984) mostraram que a atenção visual pode ser mais concentrada dentro de regiões anelares. Em seus experimentos os participantes foram instruídos a manter o olhar fixo em um ponto de fixação e identificar qual letra tinha sido apresentada em uma de três áreas delimitadas por circunferências que imitavam anéis. Uma dica informava em qual "anel" a letra apareceria. O desempenho dos participantes foi facilitado apenas quando os alvos foram mostrados dentro de um dos anéis. Quando os alvos foram apresentados na região central do campo visual, portanto, na região abrangida pelas duas circunferências, mas não dentro do anel, não existiu ganho no processamento. Esse resultado sugere que as bordas de uma região delimitada no campo visual podem ser importantes na delimitação da informação que será selecionada. Juola et al. (1987) tentaram determinar se a atenção poderia ser deslocada para regiões dentro ou fora de um circulo central e encontraram resultados parcialmente contrários aos de Egly e Homa. Estudos comportamentais e eletrofisiológicos têm demonstrado que o foco atentivo pode se moldar a regiões com formas específicas como a de uma "rosquinha" (JUOLA; BOUWHUIS; COOPER; WARNER, 1991; MULLER; HÜBNER, 2002). Esses resultados sugerem que o foco atentivo pode ser sensível à forma de 
uma região indicada e mais flexível do que os modelos inicialmente propostos (ERIKSEN; ST. JAMES, 1986; POSNER et al., 1980).

Castiello e Umiltà (1990), além de fornecer evidências sobre o ajustamento do foco atentivo ao tamanho de uma região delimitada, demonstraram que a atenção pode privilegiar o processamento de estímulos apresentados dentro de uma área específica. No segundo experimento do seu trabalho, uma moldura (quadrado) foi apresentada em dois tamanhos e o estímulo imperativo mostrado sempre em uma de cinco localizações: uma ao centro do quadrado e quatro localizações a $1^{\circ}$ grau de ângulo visual do centro. Na moldura maior, todas as cinco posições foram abrangidas pelas margens do quadrado, enquanto na moldura menor apenas a posição central poderia estar dentro. O TR foi mais lento nas provas em que o alvo foi apresentado fora dos limites da moldura, do que o TR encontrado nas provas com o alvo apresentado dentro das bordas da moldura. Castiello e Umiltà sugeriram que os estímulos apresentados dentro do quadrado foram processados mais rapidamente porque estavam dentro da região selecionada pelo foco atentivo, que não deveria se expandir além dos limites das bordas da moldura. Embora Castiello e Umiltà tenham sugerido bordas não muito definidas para o foco atentivo, seus resultados são considerados como uma evidência de que a distribuição da atenção pode ser delimitada por uma forma geométrica apresentada no campo visual (CAVE; BICHOT, 1999).

Panagopoulos, von Grünau e Galera (2004) associaram dicas endógenas com a percepção da ilusão de movimento para investigar o deslocamento atentivo de maneira voluntária, e verificaram que a atenção pode ser igualmente distribuída dentro de regiões verticais e horizontais alongadas. Seus resultados indicam que o processo de seleção pode não ser restrito a uma região circular ou oval, como 
sugerido por Eriksen e St. James (1986). Em outro estudo, Galera, von Grünau e Panagopoulos (2005), utilizando um paradigma de flankers, manipularam o tamanho e a forma de uma moldura. Os resultados mostraram um ajustamento automático da atenção à região delimitada pela figura geométrica, mesmo que os participantes tenham sido instruídos a ignorá-la. Um efeito maior dos flankers também ocorreu quando a moldura foi apresentada na horizontal do que na vertical. Essa diferença entre os dois meridianos foi interpretada como uma assimetria na distribuição dos recursos atentivos pelo campo visual, que parece ser mais concentrada no meridiano horizontal (CARRASCO; MCELREE; GIORDANO; 2002; SANDERS; BRÜCK, 1991).

Em um trabalho recente Cavallet, Rondinoni e Galera (2006), apresentaram uma moldura vertical no centro do campo visual e um alvo e dois estímulos distraidores, um de cada lado do alvo. O alvo foi apresentado sempre no centro do campo visual e uma "abertura" nas bordas do lado esquerdo e direito da moldura foi manipulada. Os resultados mostraram maior interferência dos flankers quando as bordas que separavam os flankers do alvo foram interrompidas. Nas provas em que a moldura foi apresentada completamente fechada, o efeito de incompatibilidade dos flankers praticamente desapareceu. Os resultados sugerem que na região sem as bordas da moldura, a atenção se "espalhou" além dos limites da moldura, abarcando todos os estímulos dispostos naquela região.

De maneira geral, ainda não existe na literatura um consenso sobre a forma como a seleção da informação visual ocorre em regiões com distribuições espaciais específicas, bem como, se o foco atentivo possui bordas bem definidas, capaz de se moldar a uma forma geométrica complexa. Portanto, neste estudo procuramos investigar a distribuição da atenção pelo campo visual e a possibilidade dos recursos 
atentivos serem mais concentrados no interior de uma área delimitada por uma figura geométrica de aparecimento abrupto. Para isso, utilizamos uma tarefa de julgamento de ordem temporal (JOT), que permitiu estimar a concentração de atenção destinada a uma área delimitada do campo visual. Os experimentos foram baseados no princípio de que o aparecimento abrupto de um objeto deve capturar a atenção de maneira automática (REMINGTON et al., 1992; YANTIS; JONIDES, 1984; YANTIS; JONIDES, 1990; YANTIS; JONIDES, 1996), assim como nas evidências de que o foco atentivo pode sofrer uma reorganização na distribuição dos seus recursos quando uma figura de forma geométrica específica é apresentada (CASTIELLO; UMILTÀ, 1990; CAVALET et al., 2006; EGLY; HOMA, 1984; GALERA et al., 2005; PANAGOPOULOS et al., 2004).

Uma série de estudos também tem investigado a seleção da informação visual, explorando a influência da atenção sobre a percepção de ordem temporal dos eventos visuais (HIKOSAKA; MIYAUCHI; SHIMOJO, 1993; PARK; REY; SCHLAG, 2003; SCHARLAU, 2004a; SCHARLAU, 2004b). Nesses trabalhos, uma tarefa JOT é utilizada para estimar a concentração de atenção designada a um determinado estímulo. Por exemplo, Scharlau (2004a) empregou um paradigma de JOT para investigar a possibilidade dos recursos atentivos serem distribuídos de maneira gradual fora de uma região indicada.

Um dos motivos em se usar a JOT é que esse tipo de tarefa pode fornecer uma estimativa da concentração de atenção destinada a uma região específica ou objeto localizado no campo visual, comparando a facilitação atentiva de dois estímulos localizados em regiões diferentes do campo visual (SCHARLAU, 2004b). Além disso, os resultados obtidos podem ser menos influenciados por componentes motores, pois em uma JOT a ênfase é dada sobre a precisão e não sobre a rapidez 
em realizar as respostas, como é sugerido nas tarefas de tempo de reação (COLE; GELLATLY; BLURTON, 2001).

Neste trabalho, utilizamos a tarefa JOT por que permitiu comparar o desempenho do sistema visual entre dois estímulos relevantes para a tarefa em diferentes localizações espaciais, supostamente com diferentes concentrações de recursos atentivos.

\subsection{A Tarefa de Julgamento de Ordem Temporal.}

A percepção de ordem temporal entre dois estímulos apresentados simultaneamente ou em seqüência é atribuída ao tempo que a informação sensorial de cada estímulo chega a um sistema central de comparação (STERNBERG; KNOLL, 1973). A distribuição desigual da atenção sobre os estímulos pode interferir na velocidade de transmissão da informação produzindo um efeito conhecido como entrada prioritária (prior entry effect). A idéia subjacente a esse fenômeno é comum a outros modelos atentivos descritos anteriormente, onde estímulos atendidos recebem algum privilégio no processamento da informação. No caso da hipótese da entrada prioritária, o efeito produzido pela atenção recai sobre a latência perceptual dos estímulos apresentados, ou seja, eventos atendidos devem ser percebidos antes do que estímulos não atendidos (TITCHENER, 1908).

Uma maneira utilizada pelos pesquisadores para estudar o efeito de entrada prioritária é solicitar que o observador realize um julgamento de ordem temporal de dois estímulos apresentados em seqüência ou simultaneamente. Em uma típica tarefa JOT, a atenção é deslocada para uma determinada região do campo visual, o intervalo entre a apresentação de dois estímulos relevantes para a tarefa é manipulado, e os participantes devem responder qual estímulo foi apresentado 
primeiro. Por meio da manipulação de parâmetros espaciais e temporais, os pesquisadores podem investigar a distribuição atentiva entre uma única modalidade de estímulos, como por exemplo, a visual (SHORE; SPENCE; KLEIN, 2001a; STELMACH; HERDMAN, 1991), ou entre modalidades diferentes, como por exemplo, a visual e a auditiva (SPENCE; SHORE; KLEIN, 2001b; ZAMPINI; SHORE; SPENCE, 2005).

A quantidade de atenção designada a um determinado evento, quando um JOT é solicitado, pode ser estimada pelo ponto de simultaneidade subjetiva (PSS). O PSS representa o intervalo temporal entre a apresentação dos dois estímulos a serem julgados, em que o observador está mais incerto sobre a ordem de apresentação dos estímulos. A diferença entre os PSSs dos estímulos atendidos e dos estímulos não atendidos informa a relativa aceleração perceptual (AP) do estímulo que recebeu atenção em relação ao estímulo não atendido. Um segundo parâmetro utilizado é a precisão dos participantes, que pode ser verificada pelo índice de inclinação da função utilizada para calcular os PSSs. Quanto maior a precisão no julgamento, ou resolução temporal, menor será o índice de inclinação (STERNBERG; KNOLL, 1973).

Um dos primeiros estudos a demonstrar resultados consistentes utilizando um paradigma de JOT para examinar o efeito de entrada prioritária visual, foi de Stelmach e Herdman (1991). Em seus experimentos, três localizações foram demarcadas: à esquerda, à direita e uma ao centro do campo visual. Os alvos foram sempre apresentados nas localizações demarcadas, à direita ou à esquerda, mas nunca ao centro do campo visual. Pontos movendo-se rapidamente em direção a uma das três marcas foram usados para indicar uma das localizações onde o primeiro alvo (ponto) poderia aparecer. Em seguida, os dois alvos piscavam, um no 
lado indicado e outro no lado oposto ao indicado. O intervalo entre os dois alvos (SOA) foi manipulado entre intervalos variáveis de $0,20,40,60,80$ e $100 \mathrm{~ms}$, e os participantes julgavam em qual lado o ponto aparecia primeiro. Os resultados demonstraram que o alvo apresentado no lado atendido foi percebido em média 40ms antes do que o lado não atendido. Quando a atenção foi destinada à localização central (condição neutra), não existiu aceleração perceptual para o ponto apresentado em um dos lados, ou seja, o efeito encontrado foi próximo a zero. Resultados semelhantes foram obtidos quando dicas endógenas (centrais) foram utilizadas, demonstrando que o efeito obtido não deve ser atribuído a mudanças na sensibilidade visual local, causada pela interação entre características das dicas periféricas e as características do alvo (SHORE et al., 2001a; STELMACH; HERDMAN,1991). Esses últimos resultados são fortes indícios de que a alteração na percepção de ordem temporal foi em grande parte produzida por um processo atentivo, embora não seja descartada a participação de fatores sensoriais (HADDAD; CARREIRO; BALDO, 2002; HADDAD; KLEIN; BALDO, 1999; SCHNEIDER; BAVELIER, 2003).

Apesar do efeito obtido com a JOT ser bem fundamentado, alguns estudos têm ressaltado que a aceleração perceptual encontrada pode ser influenciada por processos não sensoriais (JASKOWSKI, 1993; SCHNEIDER; BAVELIER, 2003; SHORE et al., 2001a). Quando existe incerteza a respeito da ordem de apresentação dos estímulos, o observador pode deslocar o seu critério de decisão a favor de um local atendido, respondendo mais vezes a um estímulo apresentado nesse local. Quando isso ocorre, as suas respostas são realizadas com base em um critério próprio e não sobre a percepção do evento, caracterizando um viés associado à resposta. Outros estudos têm procurado evitar esse problema 
designando ao observador uma terceira resposta, como por exemplo, o julgamento de simultaneidade (JASKOWSKI, 1993; SCHNEIDER; BAVELIER, 2003; STELMACH; HERDMAN, 1991), ou o julgamento de qual estímulo apareceu em segundo (ALLIK; KREEGIPUU, 1998; CASERTA; CAVALLET; GALERA; von GRÜNAU, 2005; SHORE et al., 2001a).

Segundo Shore et al. (2001a) uma maneira simples de acessar o viés de resposta é solicitar ao participante uma segunda tarefa JOT, oposta a primeira, que pode levar o participante a produzir uma segunda ordem de viés. A comparação entre o viés produzido nos dois tipos de julgamento pode fornecer a quantidade de tempo atribuído a esse processo não sensorial. Assim, o viés de resposta pode ser subtraído do efeito principal, obtendo-se um efeito mais confiável sobre a distribuição dos recursos atentivos pelo campo visual.

Portanto, de acordo com o nosso objetivo, se a apresentação da forma geométrica interferir na percepção de ordem temporal dos participantes, encontraremos variações nos valores dos PSSs, conforme a manipulação de características espaciais e temporais do campo visual. Isso fornecerá indícios sobre o processamento da informação dentro e fora da moldura, permitindo verificar se a atenção pode involuntariamente privilegiar o processamento dos estímulos apresentados ao longo da região delimitada pela moldura. 
2. EXPERIMENTOS 



\subsection{Experimento 1A - Percepção de ordem temporal dentro e fora de uma moldura}

Neste experimento investigamos se o aparecimento abrupto de uma figura geométrica (moldura) pode interferir na percepção de ordem temporal dos participantes. De acordo com a hipótese da entrada prioritária, o deslocamento da atenção para uma determinada região do campo visual deve provocar uma vantagem na percepção temporal dos estímulos apresentados dentro da região atendida em relação a estímulos apresentado fora dessa região (SHORE et al., 2001a; STELMACH; HERDMAN, 1991; STERNBERG; KNOLL, 1973). O método usado consistiu na apresentação de duas letras em seqüência, uma dentro da moldura e outra fora, para estimarmos a vantagem relativa da letra apresentada dentro da forma geométrica em relação à letra apresentada fora. A tarefa do participante foi responder qual letra foi apresentada primeiro, realizando uma tarefa JOT. Uma estimativa da concentração de atenção destinada a região atendida foi estimada por meio dos pontos de simultaneidade subjetiva (PSS) das letras apresentadas dentro e fora da moldura. Se a apresentação da moldura provocar uma redistribuição automática dos recursos atentivos e existir maior concentração de atenção dentro da moldura, os PSSs das letras apresentadas primeiro dentro da moldura deverão ser diferentes dos PSSs das letras apresentadas primeiro fora. A diferença entre esses dois valores fornecerá a quantidade de aceleração perceptual (AP) da letra apresenta dentro da moldura em relação à letra apresenta fora. 


\section{Método}

\section{$\underline{\text { Participantes }}$}

Oito voluntários (4 mulheres), o autor e sete estudantes do Campus da USP em Ribeirão Preto, com idade média de 25 anos, sem conhecimento prévio da proposta do trabalho, participaram de uma sessão experimental de aproximadamente 17 minutos. Todos os participantes relataram ter visão normal ou corrigida.

Material e estímulos

O experimento foi montado e executado pelo pacote de programas E`Prime® 1.0 Psychology Software Tools, Inc. (SCHNEIDER; ESCHMAN; ZUCCOLOTO, 2002) processado em um Pentium III. Os estímulos foram apresentados em um monitor Flatron 795FT Plus, com resolução de 800 x 600 pixels e taxa de atualização vertical de $100 \mathrm{~Hz}$. Os participantes permaneceram sentados em frente à tela a uma distância de aproximadamente $58 \mathrm{~cm}$.

Os estímulos, letras "F" e "J" $\left(0,3^{\circ}\right.$ x $0,4^{\circ}$ de ângulo visual e espessura da linha de $0,1^{\circ}$ ) e uma moldura (retângulo com $8,0^{\circ} \times 1,4^{\circ}$ de ângulo visual e espessura da borda de $\left.0,1^{\circ}\right)$, foram apresentados em preto $\left(0,9 \mathrm{~cd} / \mathrm{m}^{2}\right)$ sobre um fundo branco (70 $\mathrm{cd} / \mathrm{m}^{2}$ ) da tela do monitor. A moldura foi apresentada na orientação vertical à esquerda ou a direita do ponto de fixação (losango com $0,3^{\circ} \times 0,3^{\circ}$ de ângulo visual), ou na orientação horizontal, acima ou abaixo do ponto de fixação. A distância entre o ponto de fixação e o centro geométrico da moldura foi $1,1^{\circ}$ de ângulo visual e a distância entre as letras "F" e "J" foi de 2,2 (figura 1).

Quando a moldura foi apresentada na orientação horizontal acima do ponto de fixação (figura 1a), a primeira letra apresentada ( $\mathrm{F}$ ou $\mathrm{J}$ ) poderia aparecer a $1,1^{\circ}$ de ângulo visual acima do ponto de fixação (dentro da moldura) e a segunda letra a 
$3,2^{\circ}$ acima ou a $1,1^{\circ}$ de ângulo visual abaixo do ponto de fixação (fora da moldura). O contrário também ocorreu, a primeira letra poderia ser apresentada a $3,2^{\circ}$ acima ou a $1,1^{\circ}$ abaixo do ponto de fixação (fora da moldura) e a segunda a $1,1^{\circ}$ acima do ponto de fixação (dentro da moldura). As distâncias foram equivalentes quando a moldura foi apresentada abaixo do ponto de fixação. Nas provas em que a moldura foi apresentada na orientação vertical (figura 1b), as distâncias foram as mesmas de quando a moldura foi apresentada na orientação horizontal, mas desta vez a esquerda ou a direita do ponto de fixação.
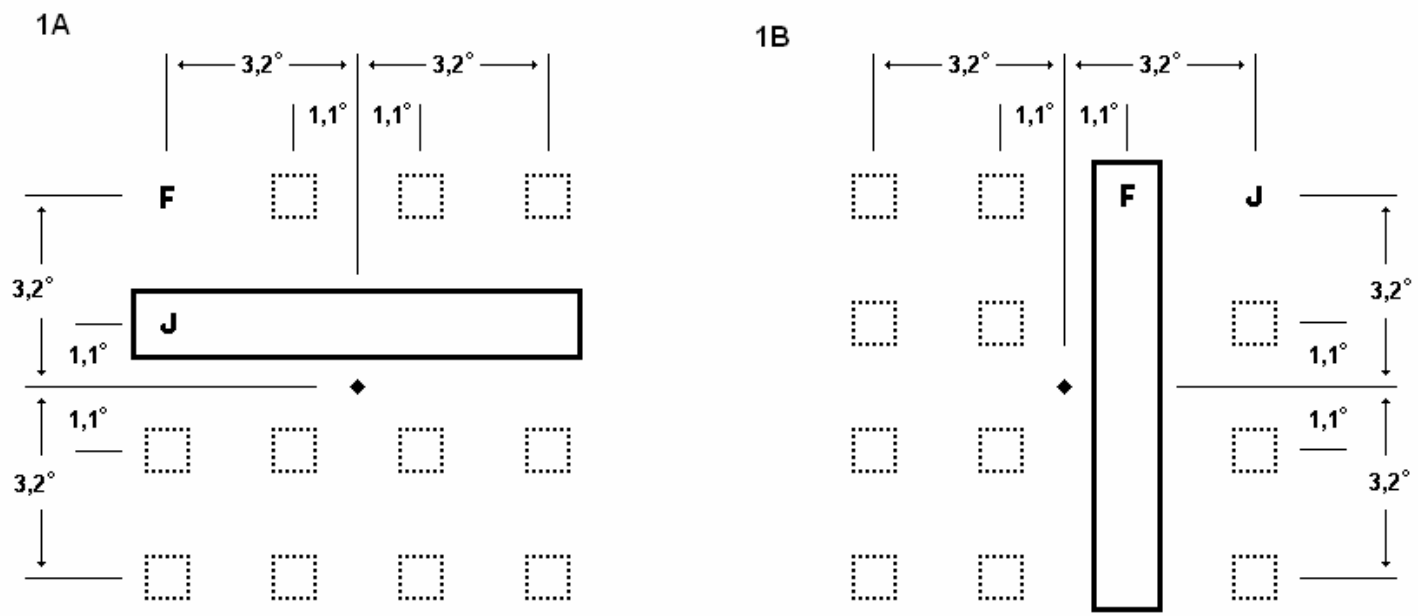

Figura 1. Estímulos utilizados no experimento 1A. As duas letras ( $F$ e J) e a moldura (retângulo) exemplificam a distância e as posições em que as letras foram apresentadas dentro e fora da moldura. A moldura poderia aparecer na orientação horizontal (figura 1a) ou na orientação vertical (figura 1b), respectivamente acima ou abaixo, a direita ou a esquerda do ponto de fixação. Os quadrados pontilhados representam as localizações em que as duas letras foram apresentadas. 


\section{Procedimento}

A tarefa do participante foi julgar qual das duas letras "F" ou "J", apresentadas em seqüência, apareceu primeiro. As respostas foram dadas no teclado do computador com os dedos indicadores (julgamento da letra "F" com o indicador esquerdo na tecla F do teclado e julgamento da letra "J" com o indicador direito na tecla J). Foram utilizados cinco intervalos entre o início da apresentação da primeira letra e o início da segunda (SOA = 20, 30, 60, 100 e 200 ms).

O participante foi instruído a realizar a tarefa o mais precisamente possível, não sendo necessário responder com rapidez. Também foi instruído a "chutar" quando estivesse incerto sobre qual estímulo havia aparecido primeiro, mantendo sempre o olhar sobre o ponto de fixação, pois isto facilitaria a sua tarefa. Os movimentos oculares não foram monitorados.

Cada prova começou com a apresentação do número da prova por 500 ms. Em seqüência, o ponto de fixação substituiu o número e após 300 ms a moldura foi apresentada. Tanto o ponto de fixação quanto a moldura, permaneceram na tela até o final da prova. A primeira letra foi mostrada depois de um intervalo de exposição da moldura de 100 ms e a segunda letra foi apresentada após um dos cinco SOAs. Depois da apresentação da segunda letra, todos os estímulos permaneceram na tela por mais 250 ms e em seguida desapareceram. Após a resposta do participante, a tela ficou em branco por mais 200 ms e em seqüência uma nova prova foi iniciada. $A$ seqüência e duração dos eventos podem ser visualizadas na figura 2 .

A letra "F" foi apresentada primeiro em $50 \%$ das provas e na outra metade "J" foi apresentada primeiro. Em $50 \%$ das provas a moldura apareceu na horizontal e na outra metade na vertical. A quantidade de vezes que cada letra foi apresentada dentro e fora da moldura foi igual. 
A orientação da moldura (horizontal e vertical), a primeira letra a ser apresentada (F ou J), a localização da primeira letra (dentro ou fora da moldura), e o SOA (20, 30, 60, 100 e 200 ms), foram apresentados aleatoriamente em 25 provas treino e em dois blocos com 250 provas teste. O participante poderia fazer um intervalo entre os dois blocos de provas teste.

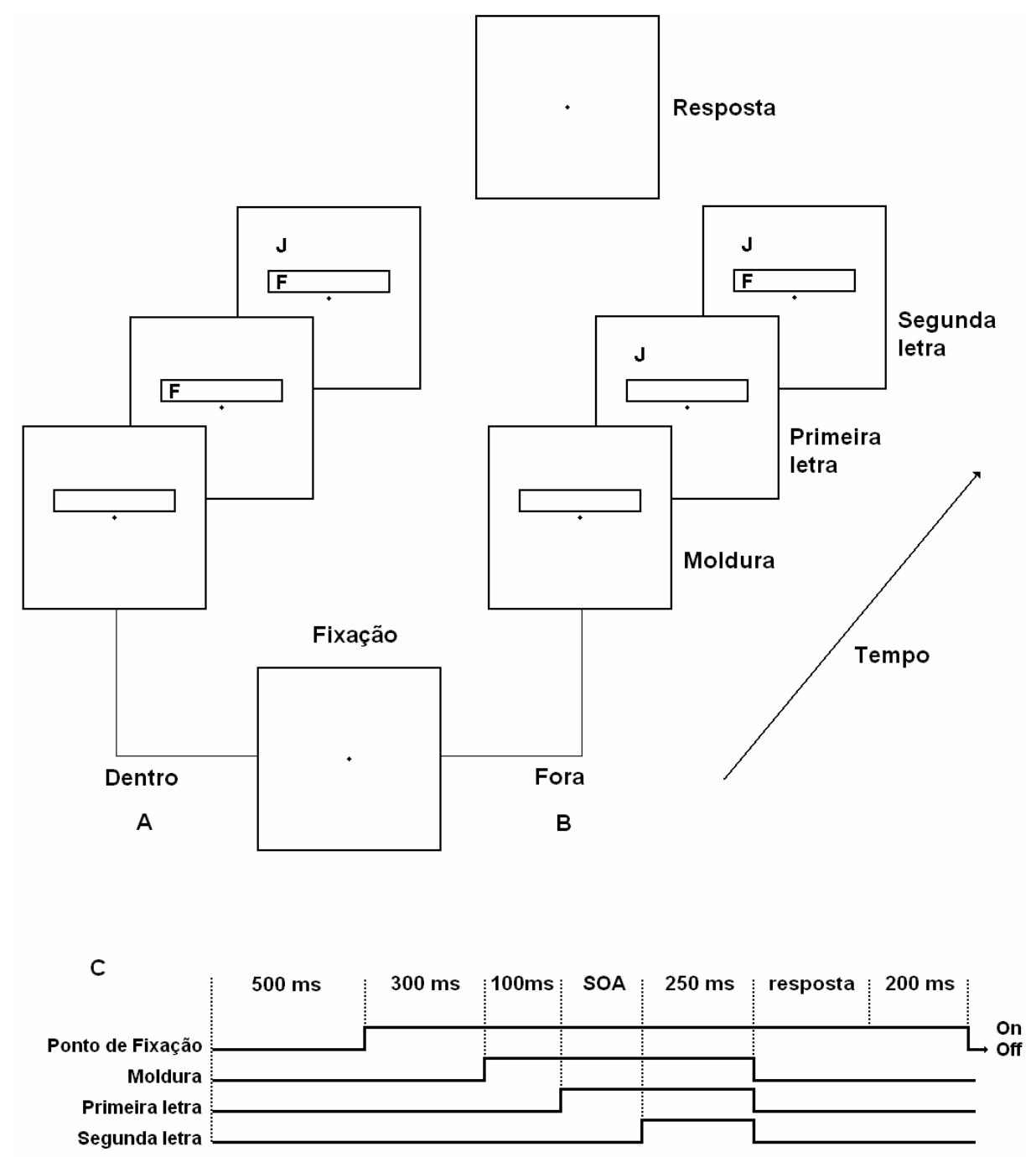

Figura 2. Seqüência de apresentação dos estímulos nas provas do experimento $1 \mathrm{~A}$. Os participantes julgaram qual das duas letras "F" ou "J" foi apresentada primeiro. A letra poderia aparecer primeiro dentro da moldura (a) ou fora da moldura (b). O SOA foi de 20, 30, 60, 100 e $200 \mathrm{~ms}$ (c). 


\section{Análise}

Provas treino e respostas muito lentas foram excluídas de novas análises. Assim como em Shneider e Bavelier (2003), as respostas a serem excluídas foram determinadas usando-se um cálculo de desvio (skew, definido pelo cociente do terceiro momento central e o cubo do desvio padrão). O desvio da distribuição do TR foi calculado para cada participante em todas as condições experimentais. Quando o desvio foi maior do que 1,2, repostas com o maior TR foram removidas até se atingir o valor de 1,2. Sujeitos com PSSs quatro vezes ou mais o desvio padrão da média não foram analisados.

A aceleração perceptual (AP) foi calculada com a metade da diferença entre os pontos de simultaneidade subjetiva (PSS) das condições em que a primeira letra apareceu dentro e quando apareceu fora da moldura. Os PSSs encontrados foram obtidos em duas etapas. Inicialmente a porcentagem de respostas "F primeiro" dentro e fora, foram calculadas para cada SOA. Em seqüência a distribuição dos valores empíricos foi ajustada à função sigmóide por meio da equação de Boltzmann, que permitiu a estimativa dos PSSs. A função de Boltzman é expressa por $Y=\left(\left(A_{1}-A_{2}\right) /\left(1+e^{(x-x 0) / d x}\right)\right)+A_{2}$, onde $Y$ é o valor a ser distribuído na curva relacionado ao SOA utilizado no experimento, $A_{1}$ são os valores de ajuste da parte inicial da curva (negativa), $A_{2}$ são os valores de ajuste da parte final da curva (positiva), e é uma constante $(\mathrm{e}=2,718282), x$ é o SOA utilizado no experimento, $x 0$ é o PSS (valor da abcissa referente aos $50 \%$ de julgamento "qual a primeira letra apresentada?"), e $d x$, valor que corresponde a inclinação da curva.

Os PSSs calculados para a posição da primeira letra (dentro e fora) e orientação da moldura (horizontal e vertical) foram submetidos a uma análise de variância (ANOVA, $p<0,05)$. Por meio de um teste $t(p<0,05)$ das médias das APs de 
todos os participantes avaliou-se a diferença entre a AP das molduras apresentadas na orientação horizontal e vertical.

\section{Resultados}

Uma média de 3,7\% das provas de cada participante foi excluída da análise devido a atrasos anormais no tempo de reação.

As funções das condições dentro e fora da moldura horizontal e vertical podem ser vistas na figura 3. Os SOAs negativos indicam que a letra "J" foi apresentada primeiro e os SOAs positivos indicam que a letra "F" foi apresentada primeiro. As setas verticais apontam os PSSs que correspondem aos $50 \%$ de respostas "F primeiro" em cada uma das funções.

A ANOVA dos PSSs para os dois fatores, posição da primeira letra (dentro, fora) e orientação da moldura (vertical, horizontal), revelou um efeito principal da posição (dentro $-43 \mathrm{~ms}$, fora $35 \mathrm{~ms})(F(1,7)=70,98 ; p<0,0001)$. Embora o efeito principal da orientação da moldura (horizontal $-6 m s$, vertical $-2 m s)(F(1,7)=3,68$; $p=0,096$ ) não possa ser considerado significativo, a interação entre posição e orientação foi significativa $(F(1,7)=6,66 ; p=0,036)$. Comparações pareadas (teste post hoc Newman-Keuls, $\mathrm{p}<0,05)$ mostraram que o PSS foi mais deslocado quando a primeira letra foi apresentada dentro da moldura horizontal $(-51 \mathrm{~ms})$, do que quando a letra foi apresentada dentro da moldura vertical (-36ms). Essa diferença não ocorre quando a primeira letra foi apresentada fora da moldura (38ms e $32 \mathrm{~ms}$, respectivamente).

Esta interação entre posição dos estímulos da tarefa JOT e a orientação da moldura, também é evidente nas APs. O teste $t$ para as APs revelou que a aceleração perceptual foi maior quando a moldura foi apresentada na horizontal 
(44ms) do que na vertical $(34 \mathrm{~ms})[t(7)=2,581 ; p=0,036]$. Isso ocorre porque a AP é a comparação entre os PSSs da condição dentro e fora, e não a média dos PSSs dentro e fora em cada condição. Neste experimento, a AP média foi de 39ms.

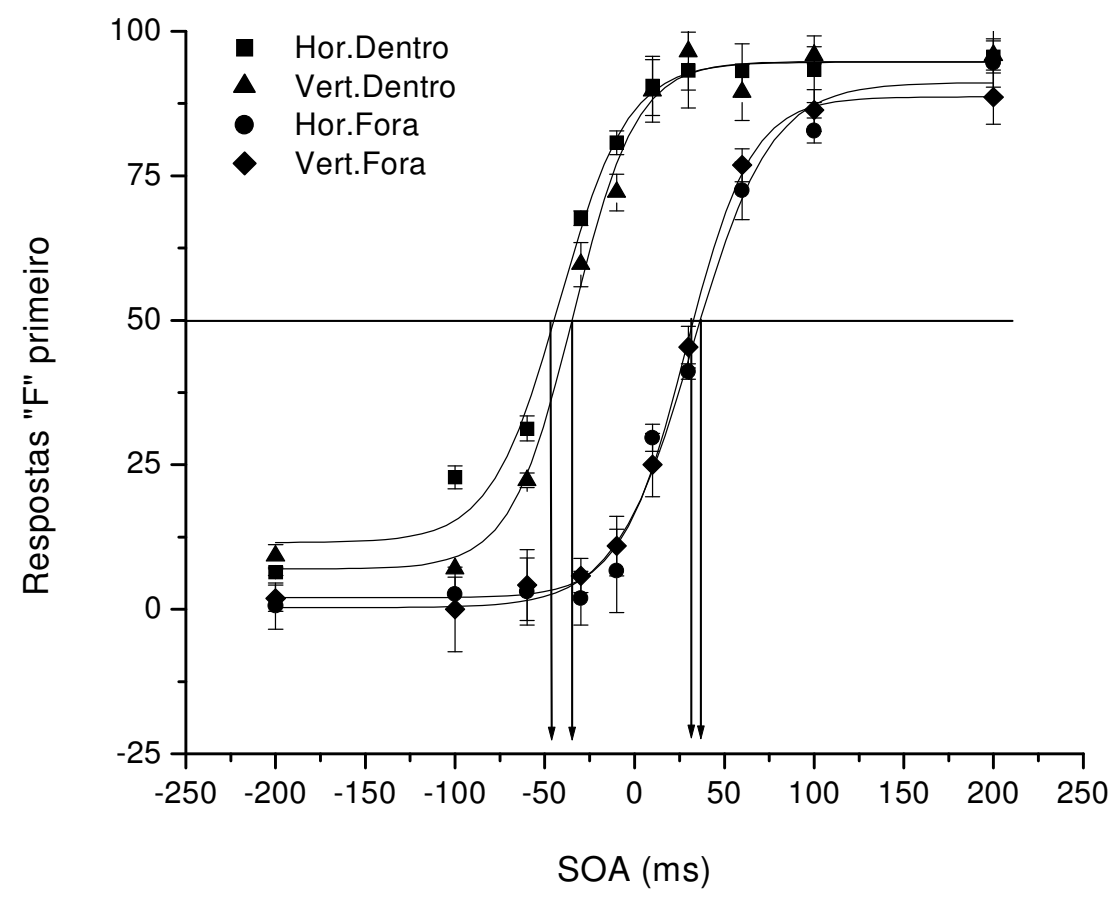

Figura 3. Ajustamento dos pontos empíricos (porcentagem média) através da função de Boltzman para as condições dentro e fora da moldura. As quatro setas verticais apontam os intervalos de tempo correspondentes aos quatro pontos de simultaneidade subjetiva (PSS) obtidos em cada função. As barras verticais representam os erros padrão da estimativa.

\section{Discussão}

Estudos mostram que o surgimento abrupto de um objeto no campo visual pode capturar a atenção de maneira involuntária (REMINGTON et al., 1992; YANTIS; JONIDES, 1984; YANTIS; JONIDES, 1990; YANTIS; JONIDES, 1996). 
Estímulos apresentados subseqüentemente no mesmo local em que esse objeto é apresentado são processados com maior eficiência e velocidade (ERIKSEN; YEH, 1985; ERIKSEN; ST. JAMES, 1986; POSNER, 1980; POSNER et al., 1980). O aumento na velocidade de transmissão da informação de um determinado estímulo pode alterar a percepção de ordem dos eventos, produzindo um efeito de entrada prioritária da informação atendida (SHORE et al., 2001a; STELMACH; HERDMAN, 1991; STERNBERG; KNOLL, 1973; TICHENER, 1908). Os resultados deste experimento parecem estar de acordo com esse princípio, mostrando um forte efeito de aceleração na percepção da ordem temporal (39 ms) sobre as letras apresentadas dentro da forma geométrica alongada, mesmo que os participantes não tenham sido instruídos a atender a moldura. $O$ efeito pode ser observado pelo deslocamento horizontal entre os PSSs médios das provas em que a letra foi apresentada dentro (-43 ms) e fora $(35 \mathrm{~ms})$ da região delimitada (figura 3). Além disso, esses dados estão próximos dos resultados de outros estudos que investigaram a hipótese de entrada prioritária visual, demonstrando que o efeito encontrado é coerente com o paradigma da JOT (HIKOSAKA; MIYAUCHI; SHIMIJO, 1993; SHORE et al., 2001a; STELMACH; HERDMAN, 1991).

A diferença entre os PSS da moldura horizontal e vertical para as letras apresentadas dentro da moldura, também sugere uma distribuição desigual dos recursos atentivos pelo campo visual. Essa diferença não ocorreu quando a primeira letra foi apresentada fora da moldura, demonstrando que a orientação da moldura interferiu no JOT apenas quando as letras foram apresentadas primeiro dentro da moldura. As APs da moldura horizontal e da moldura vertical também foram diferentes. Os valores foram mais altos para a moldura horizontal do que para a moldura vertical. A diferença encontrada entre os dois meridianos parece estar de 
acordo com os resultados de estudos que usaram tarefas de tempo de reação, e mostraram uma taxa de processamento da informação visual mais acelerada, quando estímulos relevantes para a tarefa foram apresentados no meridiano horizontal do que no vertical (CARRASCO; MCELREE; GIORDANO, 2002; SANDERS; BRÜCK, 1991). Galera et al. (2005) também encontraram uma interferência maior de flankers quando foram apresentados próximos ao alvo e dentro de uma moldura horizontal do que sobre uma moldura vertical. Esses resultados sugerem que a distribuição dos recursos atentivos pode não ser simétrica, possuindo maior concentração de atenção sobre o meridiano horizontal do que sobre o vertical, assim como os resultados encontrados neste experimento.

Apesar de a aceleração perceptual encontrada para as letras apresentadas dentro da moldura, ser atribuída a um processo atentivo, existem indícios de que o efeito encontrado pode ser influenciado por processos não perceptivos, como um viés de resposta (JASKOWSKI, 1993; SCHNEIDER; BAVELIER, 2003). Neste experimento, um exemplo desse tipo de viés pode ter ocorrido com a escolha da letra apresentada sempre dentro da moldura, toda vez que o sujeito estava incerto sobre a ordem de apresentação das letras. Adotar um critério, no caso responder sempre ao estímulo que apareceu dentro da moldura, pode ter produzido um deslocamento maior do PSS para essa condição, enviesando os resultados.

Uma maneira simples de se estimar o viés de resposta é produzir uma segunda ordem de viés (SHORE et al., 2001a). Isso é realizado solicitando-se ao observador uma segunda tarefa que deve produzir um efeito oposto sobre o viés, que não deve interferir na influência da entrada prioritária. Dessa forma, a introdução do julgamento "qual a segunda letra apresentada" pode fornecer uma aceleração perceptual contrária que permite uma estimativa da quantidade de viés. 
Os efeitos obtidos neste experimento com a apresentação da moldura também precisam ser comparados a um controle. Apesar de a moldura ter interferido na percepção de ordem temporal dos participantes, não existe uma situação neutra, sem a moldura que permita comparar os efeitos nas duas situações. Uma barra com a mesma extensão e espessura de borda da moldura, apresentada entre as duas letras, pode ser um controle para essa situação. Provavelmente, a apresentação abrupta da barra deve capturar automaticamente a atenção, mas como não possui uma forma que englobe uma determinada área, a atenção deve se espalhar igualmente pelas regiões adjacentes a barra. Nenhuma mudança na percepção de ordem temporal deve ocorrer quando a barra for apresentada, em qualquer que seja a sua orientação.

\subsection{Experimento 1B - Viés de resposta e Distribuição dos recursos atentivos}

Neste experimento o julgamento "qual a segunda letra apresentada?" foi introduzido para verificar se os resultados obtidos ocorrem da mesma maneira para o julgamento inverso de ordem temporal. A aceleração perceptual obtida no segundo julgamento pode ser comparada ao efeito encontrado no julgamento "qual a primeira letra apresentada?" e fornecer uma estimativa da quantidade de viés agregado ao nosso procedimento (SHORE et al., 2001a). Os participantes foram divididos em dois grupos e cada grupo realizou uma tarefa de julgamento oposta. Se as APs de cada tarefa forem semelhantes, o viés atribuído ao procedimento deverá ser muito pequeno.

Uma barra com mesmo comprimento e espessura de borda da moldura também foi adicionado como controle. Segundo a hipótese de entrada prioritária, na 
condição em que a barra for apresentada, os PSSs devem ser muito próximos a zero, pois as duas letras devem receber a mesma quantidade de recursos atentivos, não existindo efeito de aceleração perceptual para qualquer uma das letras (SHORE et al., 2001a; STELMACH; HERDMAN,1991).

\section{Método}

\section{$\underline{\text { Participantes }}$}

Vinte estudantes do Campus da USP em Ribeirão Preto (10 mulheres), idade entre 22 e 32 anos, divididos igualmente em dois grupos, participaram deste experimento com duração média de 45 minutos. Dois voluntários (o autor e um estudante de graduação) já tinham participado do primeiro experimento. Foi utilizado um teste de acuidade visual para verificar se a visão dos participantes estava normal. Cada participante recebeu $R \$ 5,00$ como ajuda de custo para realizar o experimento.

\section{$\underline{\text { Material e estímulos }}$}

Foram utilizados os mesmos equipamentos do experimento 1a com a exceção do teste Ortho - Rater desenvolvido por Bausch \& Lomb Incorporated que permitiu realizar o teste de acuidade visual.

Os estímulos foram os mesmos usados no experimento $1 \mathrm{~A}$, com uma diferença. Um estímulo - barra de $8,5^{\circ} \times 1,4^{\circ}$ de ângulo visual e espessura da linha de $0,1^{\circ}$ foi apresentado em preto $\left(0.9 \mathrm{~cd} / \mathrm{m}^{2}\right)$ sobre um fundo branco $\left(70 \mathrm{~cd} / \mathrm{m}^{2}\right)$ da tela do monitor. A barra apareceu na orientação vertical e horizontal, tanto à direita e a esquerda, quanto acima e abaixo do ponto de fixação. A distância entre o centro da barra e o ponto de fixação foi $2,2^{\circ}$ de ângulo visual, sempre apresentada entre as duas letras. As letras "F" e "J" foram mostradas nas mesmas distâncias e posições 
descritas no experimento $1 \mathrm{~A}$, tanto nas provas em que a barra foi apresentada, quanto nas provas em que a moldura foi apresentada.

\section{Procedimento}

Neste experimento foi acrescentado mais um tipo de julgamento ("qual o segundo estímulo apresentado?") e os participantes foram divididos em dois grupos. O participante do primeiro grupo respondeu qual letra foi percebida primeiro, enquanto o outro grupo respondeu qual letra foi percebida ou apresentada em segundo. A realização de uma tarefa excluía a participação na outra. As respostas foram dadas no teclado do computador com os dedos indicadores (julgamento da letra "F" com o indicador esquerdo na tecla $\mathrm{F}$ do teclado e julgamento da letra "J" com o indicador direito na tecla J).

A seqüência de eventos em cada prova foi igual à seqüência da prova do experimento $1 \mathrm{~A}$, com a exceção da apresentação da barra no lugar da moldura em um terço das provas (figura 4). No restante das provas a moldura foi apresentada.

A proporção de vezes que as duas letras apareceram dentro e fora da moldura foi igual (figura 4a). Quando a barra foi apresentada, as duas letras apareciam uma de cada lado da barra, mas nas mesmas posições das provas em que a moldura foi apresentada (figura 4b). Em metade das provas "F" apareceu primeiro e nos outros $50 \%$ "J" apareceu primeiro. A moldura e a barra foram apresentadas em metade das provas na orientação horizontal e na outra metade na vertical. 


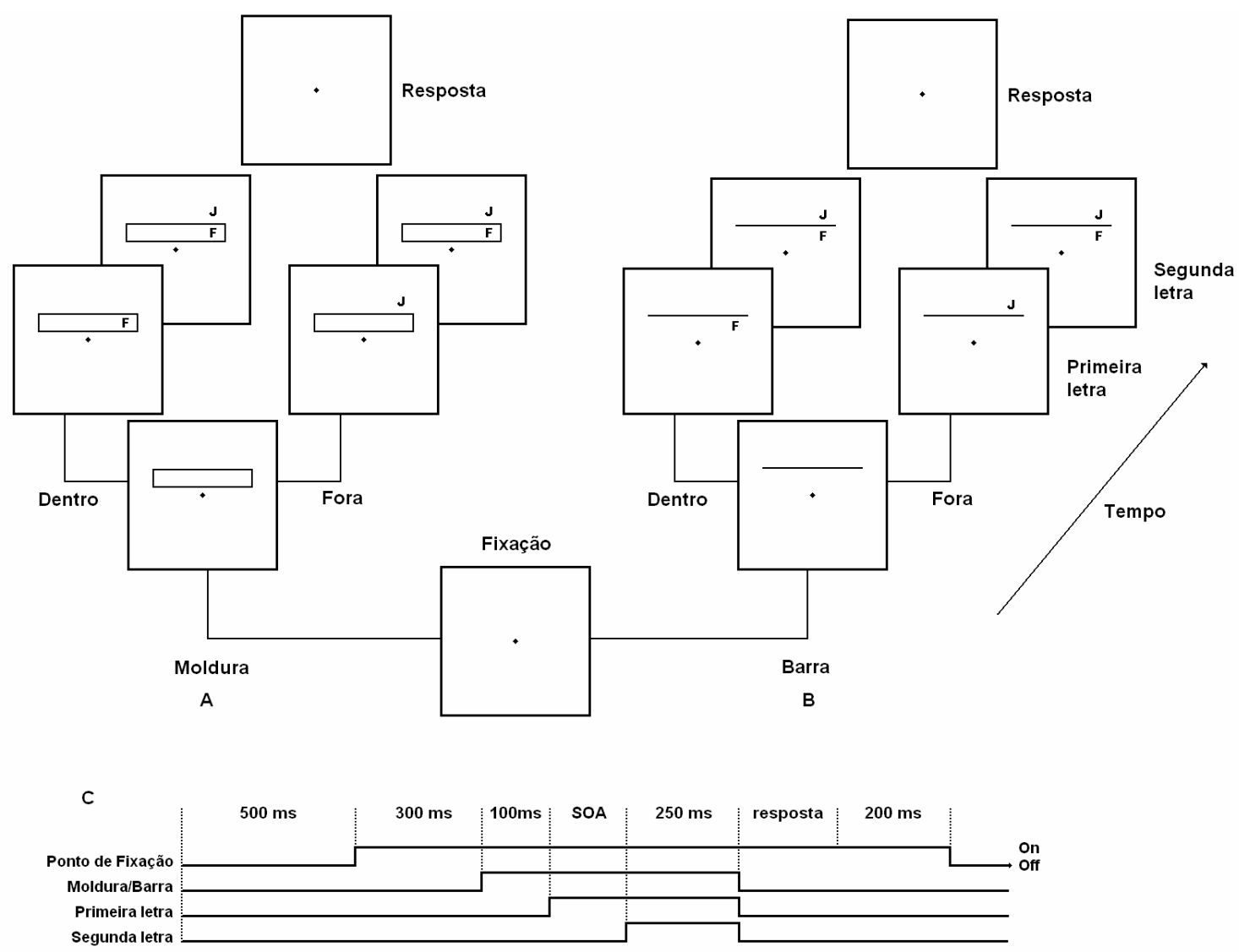

Figura 4. Seqüência de apresentação dos estímulos nas provas do experimento $1 b$. Nas provas com moldura (a), as letras foram apresentadas dentro e fora da moldura, enquanto nas provas com a barra (b), as letras foram apresentadas nas mesmas posições dentro e fora, mas sem a moldura. O SOA foi de 20, 30, 60, 100 e $200 \mathrm{~ms}$ (c).

As condições experimentais: tipo de julgamento ("qual a primeira letra apresentada?", "qual a segunda letra apresentada?"), tipo de dica (moldura, barra), localização da primeira letra (dentro, fora), orientação da moldura/barra (horizontal, vertical), primeira letra a ser apresentada $(F, J)$, localização da primeira letra (dentro, fora) e SOA (20, 30, 60, 100, $200 \mathrm{~ms})$, foram apresentados aleatoriamente e cada 
grupo participou de uma sessão experimental composta por um bloco com 20 provas treino e três blocos com 320 provas teste.

Análise

A análise foi a mesma usada no experimento $1 \mathrm{~A}$, com poucas diferenças. Devido à barra não possuir as condições dentro e fora, como na moldura, as posições dentro e fora na barra foram definidas de acordo com as posições em que as letras foram apresentadas nas provas com a moldura. Isso permitiu a análise dos PSSs das letras apresentadas na barra, de acordo com as posições dentro e fora que ocupavam. Por exemplo, nas provas com barra, a posição da letra foi definida como dentro, quando a letra aparecia na mesma posição dentro das provas com moldura. Caso aparecesse em uma posição que correspondesse a posição fora nas provas com moldura, era definida como fora para barra.

Os PSSs encontrados para as condições posição da primeira letra (dentro, fora) e orientação da moldura (horizontal e vertical) foram calculados para os dois tipos de julgamento. A contribuição do viés atribuído à resposta foi obtida pela diferença entre os efeitos de aceleração perceptual (AP) de cada tipo de julgamento (“qual a primeira letra?" e "qual a segunda letra?").

Uma ANOVA $(p<0,05)$ foi realizada para as medidas repetidas dos PSSs de cada participante levando em consideração os dois grupos independentes de julgamento ("qual o primeiro estímulo apresentado?" e "qual o segundo estímulo apresentado?") para os seguintes fatores experimentais: tipo de dica (moldura, barra), posição da primeira letra apresentada (dentro, fora) e orientação da moldura/barra (horizontal, vertical).

Outra análise de variância foi feita para as medidas repetidas das APs médias de cada participante considerando os dois grupos de julgamento como fator 
independente para as seguintes condições experimentais: tipo de dica (moldura, barra) e orientação da moldura/barra (horizontal e vertical).

\section{Resultados}

Uma média de $4,5 \%$ das provas de cada participante foi excluída de novas análises devido a atrasos anormais no tempo de reação. Dois participantes (um de cada grupo de julgamento) foram excluídos das análises por apresentarem PSSs muito fora da média (8 vezes o desvio padrão da média).

Os PSSs das condições dentro e fora, calculados para a moldura e para a barra apresentadas nas orientações vertical e horizontal, dos dois tipos de julgamento são mostrados na figura 5. No julgamento "qual a primeira letra apresentada?" a média entre os PSSs das letras que apareceram dentro da moldura horizontal (-64 ms) e vertical (-28 ms) foi -46 ms. A média entre os PSSs das letras apresentadas fora da moldura horizontal $(40 \mathrm{~ms})$ e vertical $(25 \mathrm{~ms})$ foi $32 \mathrm{~ms}$. Quando a barra foi mostrada, a média entre os PSSs das letras apresentadas nas posições dentro para a barra horizontal $(6 \mathrm{~ms})$ e vertical $(5 \mathrm{~ms})$ foi $5 \mathrm{~ms}$, e a média entre os PSSs das letras apresentadas nas posições fora para a barra horizontal ($13 \mathrm{~ms})$ e vertical (-9 ms) foi $-11 \mathrm{~ms}$.

No julgamento "qual a segunda letra apresentada?" a média entre os PSSs das letras que apareceram dentro da moldura horizontal (-30 ms) e vertical (-27 ms) foi $-28 \mathrm{~ms}$, e a média entre os PSSs das letras apresentadas fora da moldura horizontal (40 ms) e vertical (32 ms) foi $36 \mathrm{~ms}$. Quando a barra foi mostrada, a média entre os PSSs das letras apresentadas nas posições dentro para a barra horizontal (8 ms) e vertical (3 ms) foi $6 \mathrm{~ms}$, e a média entre os PSSs das letras apresentadas nas posições fora para a barra horizontal $(-7 \mathrm{~ms})$ e vertical $(-5 \mathrm{~ms})$ foi $-6 \mathrm{~ms}$. 


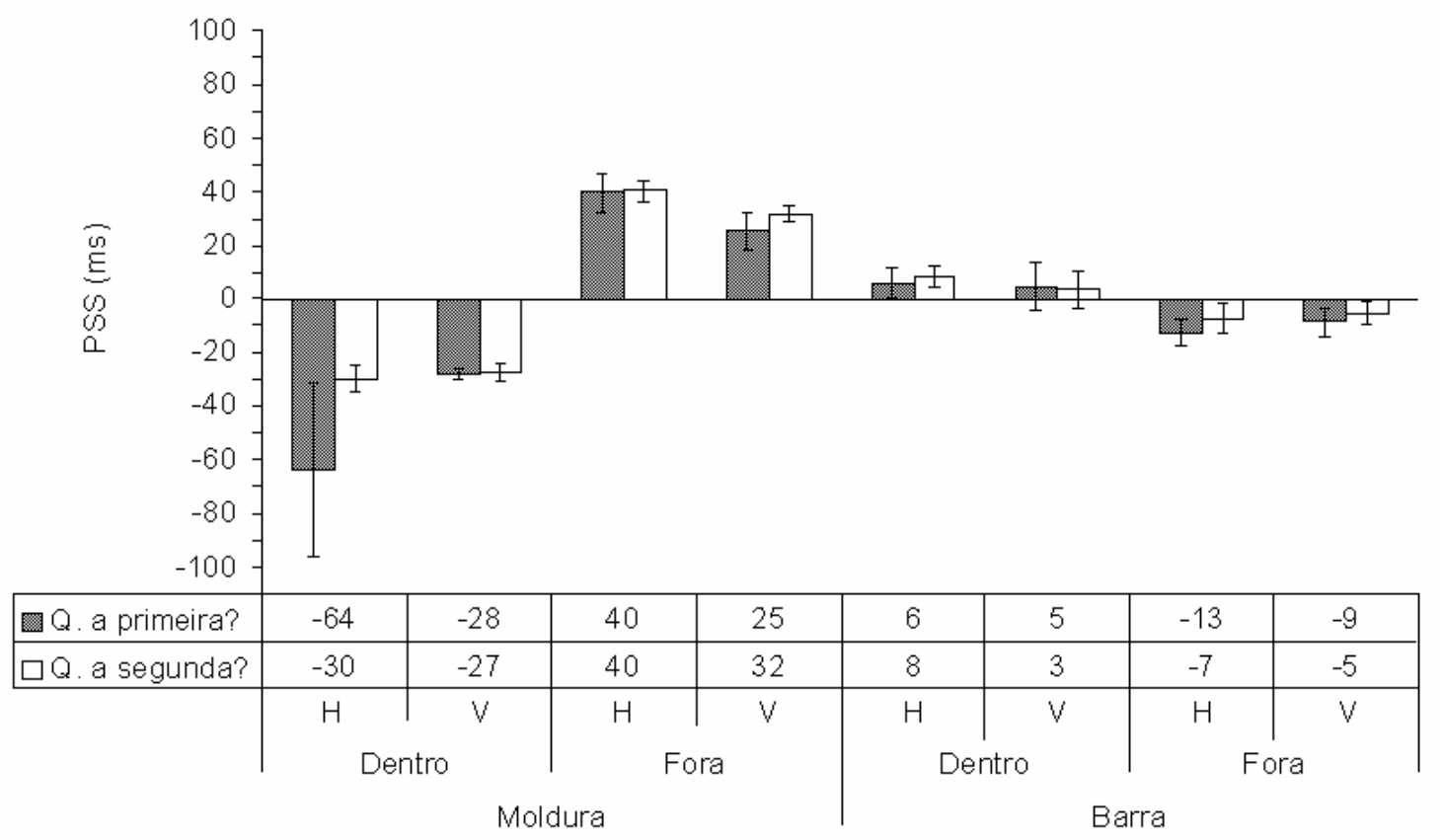

Figura 5. Pontos de simultaneidade subjetiva (PSS) médios do grupo que julgou "qual a primeira letra apresentada?" e do grupo que julgou "qual a segunda letra apresentada?", em relação ao local em que as primeiras letras foram apresentadas (dentro, fora) da moldura ou da barra nas orientações horizontal (H) e vertical (V).

A AP média da tarefa "qual letra apareceu primeiro?" foi estimado em 39 ms nas provas em que a moldura foi apresentada, sendo $52 \mathrm{~ms}$ para a moldura horizontal e $27 \mathrm{~ms}$ para a moldura vertical. Nas provas em que a barra foi apresentada, a AP média foi $-8 \mathrm{~ms}$, sendo $-9 \mathrm{~ms}$ para a barra horizontal e $-7 \mathrm{~ms}$ para a barra vertical. O grupo que julgou "qual a segunda letra apresentada?" obteve uma AP média de $32 \mathrm{~ms}$ para as provas com a moldura e - $6 \mathrm{~ms}$ para as provas com a apresentação da barra. A AP da moldura horizontal foi 35 ms e da moldura vertical $29 \mathrm{~ms}$, enquanto da barra horizontal foi $-8 \mathrm{~ms}$ e $-4 \mathrm{~ms}$ da vertical. As APs médias dos dois tipos de julgamento tanto para a moldura, quanto para a barra, apresentadas nas duas orientações, são mostrados na figura 6. A magnitude do viés 
atribuído a resposta, calculada pela diferença entre os dois tipos de julgamento, foi estimada em $7 \mathrm{~ms}$.

A ANOVA das medidas repetidas dos PSSs não mostrou diferença entre julgar "qual foi a primeira letra?" e "qual foi a segunda letra?" $(F(1,16)=1,97$; $p=0,179$ ), uma diferença significativa entre as condições dentro e fora $(F(1,16)=14,21 ; p=0,002)$, e nenhuma diferença entre a orientação horizontal e vertical $(F(1,16)=, 30 ; p=0,59)$. Apesar de não ter ocorrido diferença entre os PSSs da moldura e da barra $(F(1,16)=, 00 ; p=0,996)$, essa diferença existiu e pode ser observada na interação entre os fatores tipo de dica e posição da primeira letra $(F(1,16)=112,14 ; p<0,001)$. O teste post hoc (Newman-Keuls, $p<0,001)$ revelou que os PSSs das letras apresentadas dentro ou fora da moldura são mais deslocados negativamente e positivamente do que os PSSs das letras apresentadas nas posições dentro ou fora quando a barra foi apresentada (figura 5).

O efeito principal entre moldura e barra não é mostrado pela análise principal dos PSSs porque nessa análise são tomadas as médias das condições dentro e fora para cada uma das dicas e não a comparação entre dentro para a moldura e dentro para a barra ou o mesmo para a condição fora. Como os PSSs foram deslocados positivamente e negativamente na mesma magnitude, tanto para a condição dentro quanto para a condição fora, embora evidentemente em menor quantidade para a barra do que para a moldura (figura 5), a média será muito próxima a zero, não revelando efeito entre os dois tipos de dicas. Assim, quando a análise estatística é realizada para a vantagem relativa entre a letra apresentada dentro em relação a letra apresentada fora, para cada tipo de dica, um efeito muito significativo é encontrado entre a AP da moldura $(36 \mathrm{~ms})$ e da barra $(-7 \mathrm{~ms})(F(1,16)=112,14$; $\mathrm{p}<0,0001)$. A análise estatística da AP também mostra que não existiu diferença 
entre a aceleração perceptual dos dois grupos de julgamento $(F(1,16)=, 11 ; p=0,739)$ e nenhum efeito entre horizontal e vertical $(F(1,16)=2,36 ; p=0,144)$. Nenhuma interação ocorreu entre os três fatores.

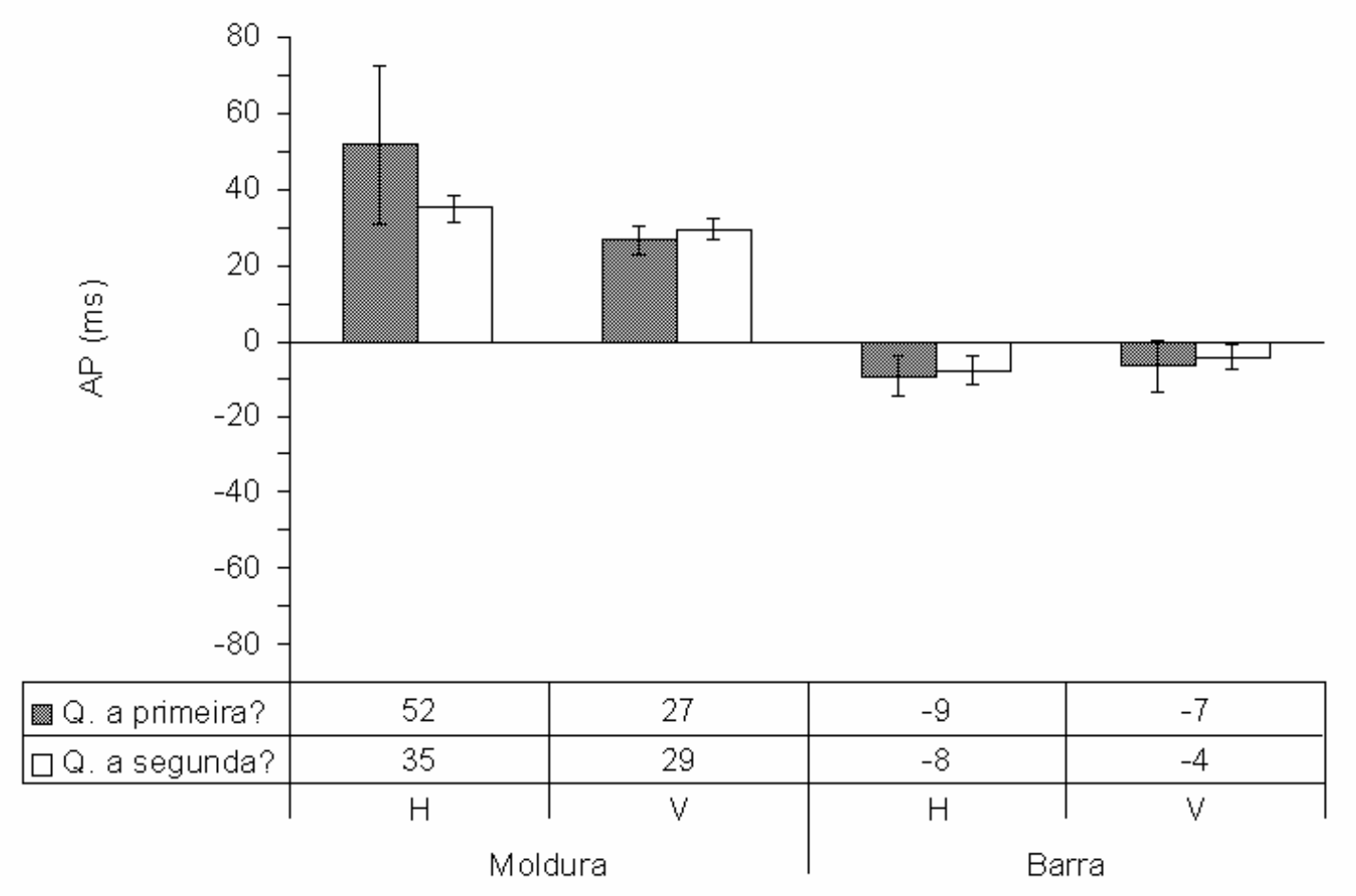

Figura 6. A aceleração perceptual (AP) média do grupo que julgou "qual a primeira letra apresentada?" e do grupo que julgou "qual a segunda letra apresentada?" nas provas com a moldura ou com a barra na horizontal $(\mathrm{H})$ e na vertical $(\mathrm{V})$.

\section{Discussão}

Os resultados mostram que o efeito produzido pela apresentação da moldura foi muito semelhante ao encontrado no primeiro experimento, confirmando os resultados anteriores. Os PSSs e as APs obtidos com o grupo de julgamento "qual a segunda letra?" revelam que mesmo sendo solicitado aos participantes um julgamento inverso, o efeito produzido pela apresentação da moldura foi igual para 
os dois tipos de tarefa. Essa ausência de variação produziu um viés de resposta estimado em $7 \mathrm{~ms}$, que foi menor do que o viés de $13 \mathrm{~ms}$ encontrado por Shore et al. (2001a). Isso sugere que mesmo que os participantes tenham adotado algum critério de resposta, esse viés interferiu pouco nos resultados.

A ausência de diferença entre os PSSs da moldura e da barra indica que o tempo necessário para os participantes perceberem a ordem temporal de apresentação das letras, diminuiu e aumentou na mesma proporção para as condições dentro e fora nos dois tipos de dica. No entanto, os PSSs foram mais deslocados para a moldura e menos deslocados nas provas em que a barra foi apresentada (figura 5). Isso pode ser observado na interação entre os PSSs dos fatores tipo de dica (moldura, barra) e posição da primeira letra (dentro, fora). Os PSSs foram bem próximos a zero quando a barra foi apresentada tanto na condição dentro quanto na condição fora, enquanto os PSSs da moldura foram bem deslocados. Essa diferença é mais evidente entre as APs da moldura e da barra, pois são a relativa aceleração da letra apresentada dentro da moldura em relação a letra apresentada fora (figura 6). Os valores demonstram que as letras apresentadas dentro da moldura tiveram um efeito de aceleração perceptual de $36 \mathrm{~ms}$, enquanto o efeito produzido pela barra foi de $-7 \mathrm{~ms}$. Resultados semelhantes foram obtidos por Shore et al. (2001a) e por Stelmach e Herdman (1991) ao indicarem uma posição no centro do campo visual quando os alvos a serem julgados apareciam no lado direito ou esquerdo. Os PSSs da situação neutra não foram diferentes de zero e diferiram da condição em que um dos alvos foi indicado.

Considerando-se que o aparecimento abrupto da barra atraiu a atenção, esses resultados confirmam a hipótese de que as duas letras receberam a mesma quantidade de recursos quando a barra foi apresentada. O mesmo não ocorreu com 
a moldura, reforçando a idéia de que a atenção pode ser mais concentrada dentro das bordas da moldura (CASTIELLO; UMILTÀ, 1990).

Um resultado não esperado foi a ausência de diferença entre a orientação vertical e horizontal da moldura. No grupo que julgou "qual a primeira letra" ainda existiu uma diferença de $36 \mathrm{~ms}$ entre os PSSs das duas condições, mas essa diferença não alcançou a relevância estatística. O mesmo ocorreu entre as APs da moldura horizontal e vertical do mesmo grupo. Uma análise mais detalhada revelou que esse resultado segue a mesma tendência em todos os participantes. A ocorrência deste efeito apenas no experimento $1 \mathrm{~A}$ e não no grupo que realizou 0 mesmo julgamento neste experimento, pode ser atribuída a apresentação da barra em um terço das provas, que influenciou a distribuição dos recursos atentivos ao longo das provas. A moldura pode ter perdido parte do efeito sobre a concentração da atenção. Folk, Remington e Johnston (1992) verificaram que a manipulação da validade da dica em tarefas de tempo de reação simples, diminuía a influência da dica sobre o RT. Esses autores sugeriram que sobre condições de incerteza espacial, o sistema de deslocamento exógeno da atenção pode ser "ajustado" para responder seletivamente às propriedades dos estímulos relevantes para a tarefa. Isso pode ter ocorrido com a introdução da barra, que no número total de provas, aumentou a incerteza sobre o local em que as letras foram apresentadas. Isso pode ter mudado o "ajustamento" do sistema, tornando-o menos sensível a extensão da moldura. A atenção pode ter sido mais concentrada sobre a região próxima às duas letras. Quando a moldura foi apresentada, os recursos atentivos podem não ter se "espalhado" ao longo de toda a moldura, diminuindo o efeito encontrado para a moldura horizontal. 
O processamento privilegiado da informação apresentada dentro da moldura, leva a interpretação de que o objeto desempenhou importante papel na seleção da informação visual (BAYLIS; DRIVER, 1993; DUNCAN, 1984; GIBSON, 1994; KAHNEMAN; TREISMAN; GIBBS, 1992; KRAMER; JACOBSON, 1991). Duncan (1984) utilizando dois objetos sobrepostos observou que estímulos apresentados dentro do objeto atendido, recebiam prioridade no processamento em relação aos estímulos apresentados no objeto que não recebia atenção. Assim, neste experimento, pode ser que a letra apresentada dentro da moldura foi percebida primeiro, por que estava dentro de um objeto que recebeu atenção, independente da sua orientação espacial (DUNCAN, 1984; SHOMENSTEIN; YANTIS, 2002). No entanto, o fato de existir apenas uma moldura e em todas as provas a localização espacial dos estímulos mudar prova a prova, não permite afirmar se a seleção ocorreu baseada apenas no objeto. Vários estudos têm se dedicado a essa questão, verificando que a seleção da informação relevante para o indivíduo pode ser realizada de maneira conjunta, ou seja, dada a importância da localização espacial e às características dos objetos que serão selecionados, o sistema visual pode processar esses dois tipos de informação em áreas diferentemente especializadas (EGLY; DRIVER; RAFAL, 1994), como também, integrá-las de acordo com a especificidade da tarefa (VECERA; FARAH, 1994). Lavie e Driver, (1996), sugerem que no processo de seleção, a distribuição da atenção visual pode ocorrer no espaço, sendo influência pelas características dos objetos. Nós trabalhamos com a possibilidade do foco atentivo se ajustar não só ao tamanho dos objetos, mas também a forma. Essa idéia também considera tanto a localização espacial dos estímulos, quanto as características dos objetos, uma vez que os objetos ocupam um lugar no espaço (GALERA et al., 2005; PANAGOPOULOS et al., 2004). As 
bordas alongadas que delimitam uma região, podem ser processadas pelo sistema visual como um objeto, no qual o foco da atenção se ajusta, priorizando a informação apresentada dentro dessa região delimitada.

Levando-se em consideração a maneira como os estímulos foram apresentados, uma outra questão pode ser levantada a respeito da contribuição da excentricidade das letras apresentadas dentro e fora da moldura sobre os PSSs. Estudos demonstram que a distância entre o ponto de fixação e os estímulos a serem julgados, influencia a percepção de ordem temporal (HADDAD; KLEIN; BALDO, 1999; HADDAD; CARREIRO; BALDO, 2002). Segundo esses trabalhos, alvos mais distantes da fixação inicial da atenção (ponto de fixação) são percebidos depois do que alvos apresentados no centro ou em locais mais próximos do pondo de fixação. Isso confirma a prioridade do processamento atentivo para estímulos apresentados dentro da região coberta pela fóvea. No experimento anterior, em metade das provas, as letras foram apresentadas a diferentes distâncias do ponto de fixação. Isso pode ter contribuído para uma aceleração perceptual da letra apresentada mais ao centro do campo visual. Essa questão foi investigada no próximo experimento, junto à manipulação da distância espacial entre os dois estímulos relevantes para a tarefa JOT. A manipulação da distância espacial entre as duas letras pode fornecer mais informações sobre a seleção da informação dentro e fora da moldura.

\subsection{Experimento 2 - Gradiente de distribuição espacial da atenção}

Neste experimento a distância espacial entre o estímulo apresentado dentro e o estímulo apresentado fora de uma moldura foi manipulada. O objetivo foi verificar 
se a distribuição dos recursos atentivos ao longo da moldura é influenciada pela distância entre as duas letras. Trabalhos utilizando tarefas de tempo de reação demonstram que a distância entre uma região indicada e o alvo pode interferir no desempenho dos participantes (ERIKSEN; YEH, 1985; LABERGE, 1983, LABERGE; BROWN, 1989; POSNER et al., 1980; ZIMBA; HUGHES 1987). Apesar das diferentes suposições sobre as características do tamanho e das bordas do campo atentivo, esses estudos consideram que a aceleração perceptual produzida pela atenção diminui com o distanciamento do alvo em relação ao centro do foco atentivo. Poucos estudos exploraram esse efeito usando o paradigma da JOT. A manipulação da distância entre os dois estímulos relevantes para a tarefa JOT pode ser uma boa possibilidade de investigarmos a concentração de recursos atentivos, variando a distância entre dois eventos relevantes para a tarefa. A JOT pode fornecer informações sobre a precisão (inclinação da curva) e a vantagem relativa obtida pelo estímulo atendido sobre o estímulo não atendido.

Semelhante ao que foi feito neste experimento, Scharlau (2004a) usou um paradigma de JOT para verificar se a atenção poderia ser distribuída de maneira gradual pelo campo visual. Em seu estudo, uma dica e dois estímulos de comparação foram apresentados a uma mesma distância do ponto de fixação, formando uma circunferência imaginária com raio de $6,5^{\circ}$, que permitiu a manipulação da distância espacial entre os dois alvos e o controle da excentricidade. Em seus experimentos, a distância entre os dois estímulos a serem julgados variou desde $1,3^{\circ}$ até $13^{\circ}$ de ângulo visual. A distância entre a dica e os dois alvos tæmbém foi manipulada. Os resultados não mostraram uma variação suficiente dos PSSs que comprovassem uma distribuição gradativa da atenção conforme o aumento da distância entre os dois estímulos de comparação. Um efeito gradativo só foi 
encontrado quando a dica e os dois estímulos permaneceram expostos na tela até que o participante realizasse a sua resposta.

Neste experimento, a forma geométrica alongada utilizada nos experimentos anteriores foi trocada por um quadrado. Essa alteração permitiu um controle maior sobre a distância entre as duas letras e o centro geométrico do quadrado, além de manter a mesma distância do ponto de fixação. Isso permitiu um controle sobre a excentricidade dos estímulos. O método foi o mesmo utilizado nos experimentos $1 \mathrm{~A}$ e 1B. Uma letra foi apresentada dentro e a outra fora do centro geométrico da moldura. A letra apresentada fora apareceu próxima ou distante da moldura.

Considerando-se a distribuição automática da atenção para a moldura e a variação inversamente proporcional de recursos atentivos em função da distância, a concentração de recursos deve diminuir gradualmente da moldura (região com maior concentração de recursos atentivos) para o restante do campo visual. Quanto mais distante a letra for apresentada da moldura, menos recursos atentivos terá. Deste modo, a facilitação da primeira letra deve ser maior quando for apresentada dentro da moldura e diminuir com o aumento da distância quando for apresentada fora. Em relação à segunda letra, a facilitação será maior quanto mais próxima estiver da moldura. Os PSSs devem ser menos deslocados quando as letras forem apresentadas próximas e mais deslocados quando forem apresentas distantes uma da outra. Como a AP é a relativa aceleração da letra que está dentro da moldura em relação à letra que está fora, será reduzida quando a distância for curta e o contrário quando for longa. Ainda de acordo com essa hipótese, os participantes devem ser menos precisos quando a distância entre as duas letras for maior do que quando for curta. 


\section{Método}

\section{$\underline{\text { Participantes }}$}

Dezessete estudantes do Campus da USP em Ribeirão Preto (11 mulheres), idade média de 24 anos participaram deste experimento com duração média de 30 minutos. Seis voluntários já haviam participado de um dos experimentos anteriores e não precisaram realizar o mesmo teste de acuidade visual usado no experimento anterior. Cada participante recebeu $\mathrm{R} \$ 5,00$ para participar do experimento.

\section{Material e estímulos}

Foram utilizados os mesmos materiais e estímulos do experimento $1 \mathrm{~A}$, com uma exceção, no lugar do retângulo um quadrado foi apresentado como moldura $\left(1,8^{\circ} \times 1,8^{\circ}\right.$ de ângulo visual e espessura da borda de $\left.0,1^{\circ}\right)$.

Para controle da excentricidade dos estímulos, o centro geométrico da moldura e as duas letras "F" e "J" foram apresentadas a uma mesma distância do ponto de fixação formando uma circunferência imaginária com raio $4,1^{\circ}$ de ângulo visual. Em cada prova a moldura e as duas letras poderiam aparecer em duas de 12 localizações fixas ao redor do ponto de fixação, sempre à esquerda ou à direita, acima ou abaixo do ponto de fixação (figura 7). Uma das letras foi sempre apresentada dentro da moldura e a outra fora. Duas distâncias entre "F" e "J" foram usadas: uma menor de $1,9^{\circ}$ de ângulo visual (lado esquerdo da figura 7 ) e outra maior de $5,7^{\circ}$ de ângulo visual (lado direito da figura 7 ). Os pares de quadrados pontilhados na figura 7 representam as possíveis localizações em que os estímulos foram apresentados. 

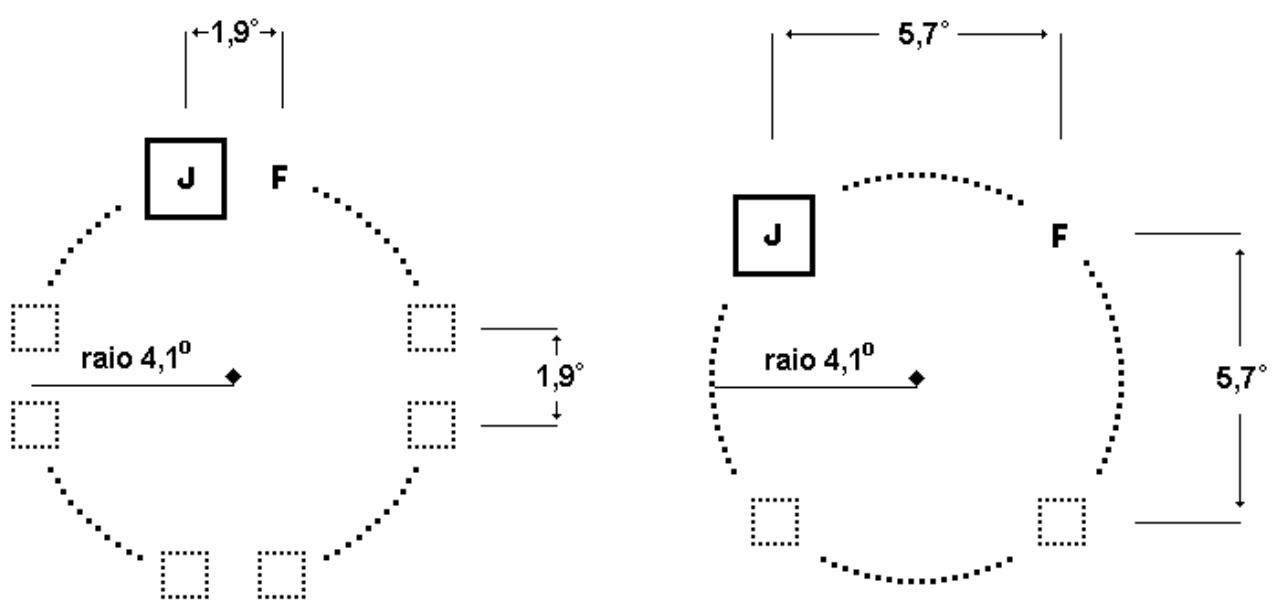

Figura 7. Estímulos e distâncias utilizados no experimento 2. O centro geométrico da moldura e as duas letras foram sempre apresentados a $4,1^{\circ}$ de ângulo visual do ponto de fixação formando uma circunferência imaginária. Os quadrados pontilhados representam os possíveis locais em que as duas letras poderiam aparecer.

\section{Procedimento}

A tarefa do participante foi igual a do experimento $1 \mathrm{~A}$, ou seja, julgar qual letra foi apresentada primeiro e as respostas foram dadas no teclado do computador.

A seqüência de eventos das provas foi igual a do experimento $1 \mathrm{~A}$ com três exceções. Em cada prova, o participante pressionou a tecla de espaço do teclado para começar a apresentação dos estímulos, o tempo de exposição do número da prova foi reduzido de 500 ms para 300 ms e, após o participante realizar a resposta, o ponto de fixação mudou para a cor azul, sinalizando ao participante o término da prova. Os participantes foram instruídos a realizar a pausa para descanso, somente quando o ponto de fixação estivesse azul e os movimentos oculares não foram monitorados.

A letra " $F$ " foi apresentada primeiro em $50 \%$ das provas ( $25 \%$ dentro e $25 \%$ fora da moldura), na outra metade das provas "J" foi apresentada primeiro ( $25 \%$ 
dentro e $25 \%$ fora da moldura). A primeira letra apresentada ( $F$ ou J), a localização da primeira letra (dentro ou fora da moldura), distância entre as duas letras $\left(1,9^{\circ}\right.$ ou $5,7^{\circ}$ de ângulo visual) e o SOA $(20,30,60,100$ e $200 \mathrm{~ms})$ foram aleatoriamente apresentados em 20 provas treino e 640 provas teste.

Análise

Os PSSs das condições dentro e fora da moldura, e distância menor e maior, foram calculados a partir dos mesmos passos do experimento $1 \mathrm{~A}$. A diferença entre cada PSS das distâncias apresentadas dentro e fora da moldura forneceu as APs de cada distância entre as letras.

Assim como Scharlau (2004a), a precisão dos participantes no julgamento de ordem temporal para cada distância foi obtida através da inclinação da função (dx da função de Boltzman). Como a inclinação é determinada pela precisão dos participantes em discriminar a ordem temporal de apresentação dos estímulos, quanto maior o número de acertos, menos dispersa será a curva (STERNBERG; KNOLL, 1973).

As medidas repetidas dos PSSs de cada participante dos dois fatores, localização da primeira letra (dentro, fora da moldura) e distância entre as duas letras $\left(1,9^{\circ}, 5,7^{\circ}\right)$ foram submetidas a uma ANOVA $(p<0,05)$. As APs das duas distâncias e os índices de inclinação das funções, obtidos para cada distância, foram submetidas a testes $t(p<0,05)$ separados.

\section{Resultados}

Dois participantes foram excluídos de novas análises devido a PSSs muito acima da média (4 vezes o desvio padrão da média). A porcentagem média de provas excluídas devido a tempos de reação muito longos foi $6,4 \%$. 
A análise estatística dos PSSs mostrou que existe diferença entre apresentar a letra dentro $(-38 \mathrm{~ms})$ ou fora $(38 \mathrm{~ms})$ da moldura $(F(1,14)=36,07 ; p<0,0001)$, a distância entre as duas letras não produziu diferença significativa $\left(1,9^{\circ}=-1 \mathrm{~ms}, 5,7^{\circ}\right.$ $=1 \mathrm{~ms})(F(1,14)=, 24 ; p=0,633)$, no entanto, ocorreu uma interação entre a localização da primeira letra e distância entre as duas letras $(F(1,14)=5,63 ; p=0,033)$. O teste de Newman-Keuls $(p<0,05)$ revelou que existiu diferença entre os PSSs das letras apresentadas a $1,9^{\circ}$ (-34 ms) e 5,7 (-42 ms) quando uma das letras foi mostrada primeiro dentro da moldura, e uma tendência entre as duas distâncias $\left(1,9^{\circ}=32 \mathrm{~ms}\right.$ e $\left.5,7^{\circ}=44 \mathrm{~ms}\right)$ para a letra apresentada primeiro fora (figura 8 ).

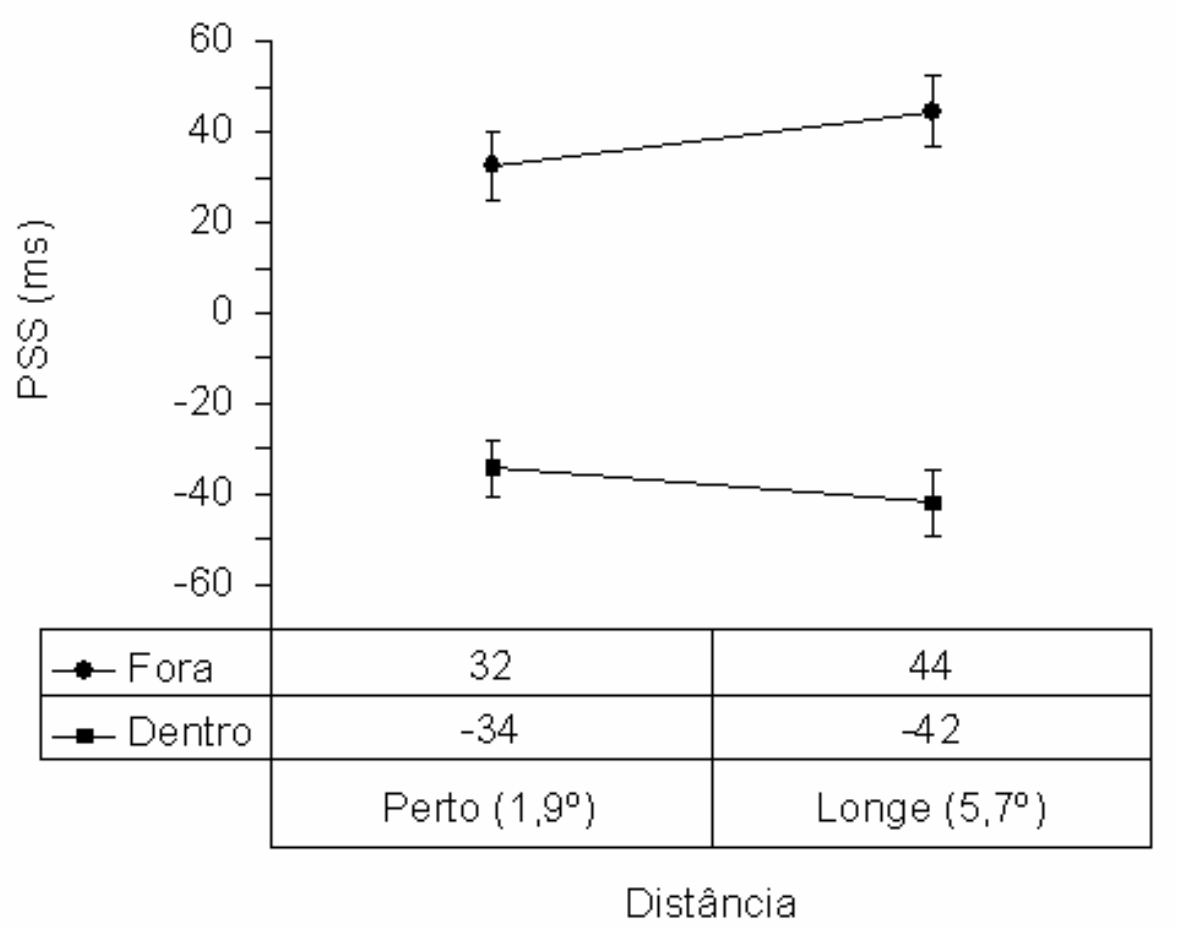

Figura 8. Pontos de simultaneidade subjetiva (PSSs) das provas em que uma das letras foi apresentada primeiro dentro ou fora da moldura em relação a distância, perto $\left(1,9^{\circ}\right)$ ou longe $\left(5,7^{\circ}\right)$, da segunda letra. 
O índice de inclinação médio da curva quando as letras foram apresentadas a distância de $1,9^{\circ}$ uma da outra foi $18 \mathrm{~ms}$, sendo menor do que o índice de inclinação das letras apresentadas a $5,7^{\circ}$ de ângulo visual, que foi $32 \mathrm{~ms}(t(14)=-3,12$, $\mathrm{p}=0,007)$. A AP média foi menor (33 ms) para as letras apresentadas próximas $\left(1,9^{\circ}\right)$ e maior (43 ms) para as letras apresentadas mais distantes $\left(5,7^{\circ}\right)$ uma da outra $(t(14)=-2,4, p=0,033)$. A AP geral produzida pela moldura foi estimada em $38 \mathrm{~ms}$.

\section{Discussão}

A diferença entre os PSSs das condições dentro e fora demonstra que a moldura foi mais uma vez capaz de influenciar o JOT, acelerando em 38 ms a percepção de ordem da letra apresentada dentro das bordas da figura geométrica. A comparação entre os PSSs das condições dentro e fora mostrou que a manipulação da distância entre as duas letras, alterou da mesma maneira a percepção de ordem temporal dos participantes quando a primeira letra foi apresentada dentro, ou quando foi apresentada primeiro fora da moldura. Isso é observado na figura 8 com o aumento igual do deslocamento vertical dos PSSs das condições dentro e fora, em relação ao aumento da distância. A análise dos fatores posição e distância revelou que a distância alterou o JOT apenas quando a letra foi apresentada primeiro fora da moldura, produzindo um efeito marginal sobre os PSSs. No entanto, quando a letra foi apresentada primeiro dentro, nenhum efeito foi encontrado. Esses resultados sugerem que os participantes levaram mais tempo para julgar a letra apresentada mais distante, estando de acordo com a idéia de que existe maior facilitação perceptual para os estímulos apresentados mais próximos da moldura.

Outro resultado que indica alteração na percepção em função da distância, foi a inclinação das curvas, mostrando que os participantes foram mais precisos quando 
a distância foi menor entre as duas letras. Quando a distancia aumentou, tornou-se mais difícil julgar qual letra foi apresentada primeiro, diminuindo os acertos. Estes resultados estão relacionados a menor AP encontrada para a menor distância do que para a maior distância. A maior facilidade em julgar a ordem temporal a curta distância diminuiu a vantagem relativa da letra apresentada dentro da moldura, o que é observado na aceleração perceptual menor quando as letras foram apresentadas a $1,9^{\circ}$, do que a 5,7ํำ de ângulo visual (figura 8).

Os resultados reforçam a hipótese de que existe maior concentração de recursos atentivos dentro dos contornos da moldura, pois a vantagem na percepção de ordem temporal variou em função da distância, um efeito relatado para a distribuição espacial da atenção visual. Os dados também demonstram que a distância entre os dois estímulos alvo é um fator importante para a percepção de ordem temporal, influenciando o JOT. Além disso, como as letras foram apresentadas a uma mesma distância do ponto de fixação, a facilitação atentiva encontrada não deve ser atribuída a diferentes excentricidades entre as duas letras, como foi discutido no experimento $1 \mathrm{~B}$.

Os resultados foram diferentes daqueles apresentados por Scharlau (2004a), que não encontrou um gradiente atentivo manipulando a distância entre os dois alvos. Nos experimentos 1 e 2 de Scharlau os estímulos foram expostos muito rapidamente, enquanto no presente experimento a moldura e os dois estímulos de comparação ficaram expostos até que o participante realizasse a sua resposta. Scharlau encontrou um efeito gradativo apenas quando os estímulos permaneceram na tela até que os participantes realizassem a sua resposta, da mesma forma demonstrada aqui. Provavelmente, quando o campo visual está vazio a atenção pode ser mais dificilmente destinada a uma região específica, do que quando 
existem objetos presentes. Essa idéia concorda com a os resultados de Turatto et al. (2001), que mostraram um ajustamento do foco atentivo a uma região delimitada, apenas quando as margens dessa região estavam presentes no campo visual. Zimba e Hughes (1987) também encontraram evidências de uma distribuição espacial da atenção, apenas quando as prováveis posições dos alvos foram demarcadas por pontos de referência. Quando o campo visual estava vazio, nenhum efeito foi encontrado.

Considerando que a atenção possa se ajustar automaticamente à área delimitada pela moldura e que a facilitação proporcionada pela atenção, compreende uma fase inicial transitória, seguida por um componente voluntário que pode se estender por mais tempo (CHEAL; LYON, 1991; MÜLLER; RABBITT, 1989; NAKAYAMA; MACKEBEN, 1989), uma outra questão investigada neste trabalho referiu-se ao tempo necessário para os recursos atentivos produzirem maior efeito de aceleração perceptual sobre a letra apresentada da figura geométrica alongada. Isso forneceria indícios sobre a variação da concentração de atenção sobre a moldura em função de um determinado intervalo de tempo.

\subsection{Experimento 3 - Dinâmica temporal da atenção visual}

No experimento 3 investigamos o julgamento de ordem temporal em função do tempo de exposição da moldura. Se o aparecimento abrupto da moldura é capaz de capturar automaticamente a atenção e existe um intervalo em que ocorre máxima ativação atentiva, provavelmente a manipulação do tempo de exposição da moldura deve fornecer evidências de uma variação de maior e menor aceleração perceptual. 
Neste experimento, a moldura foi apresentada antes da primeira letra durante um intervalo variável de tempo, de 50 a 400 ms. Essa extensão de tempo deve fornecer uma amostra da variação da atenção exógena dentro e fora da moldura (CHEAL; LYON, 1991; MÜLLER; RABBITT, 1989; NAKAYAMA; MACKEBEN, 1989). A aceleração perceptual deve alcançar um efeito máximo por volta de 100 ms após o início da apresentação da dica e diminuir por volta de 400 ms (SCHNEIDER; BAVELIER, 2003; SHORE et al., 2001a; STELMACH; HERDMAN, 1991).

\section{Método}

\section{$\underline{\text { Participantes }}$}

Quinze estudantes (5 mulheres), idade média de 24 anos, participaram deste experimento com duração média de 45 minutos. Os participantes passaram pelo mesmo teste de acuidade visual adotado no primeiro experimento. Cada participante recebeu $R \$ 5,00$ como ajuda de custo para realizar o experimento.

Material e estímulos

Neste experimento foi utilizado o mesmo material e estímulos do experimento 1A. Uma alteração foi realizada quanto à distância das letras em relação ao ponto de fixação. A letra apresentada dentro da moldura e a letra apresentada fora, foram mostradas sempre a mesma distância do ponto de fixação. As distâncias foram as mesmas utilizadas no experimento 1A (figura 9). 

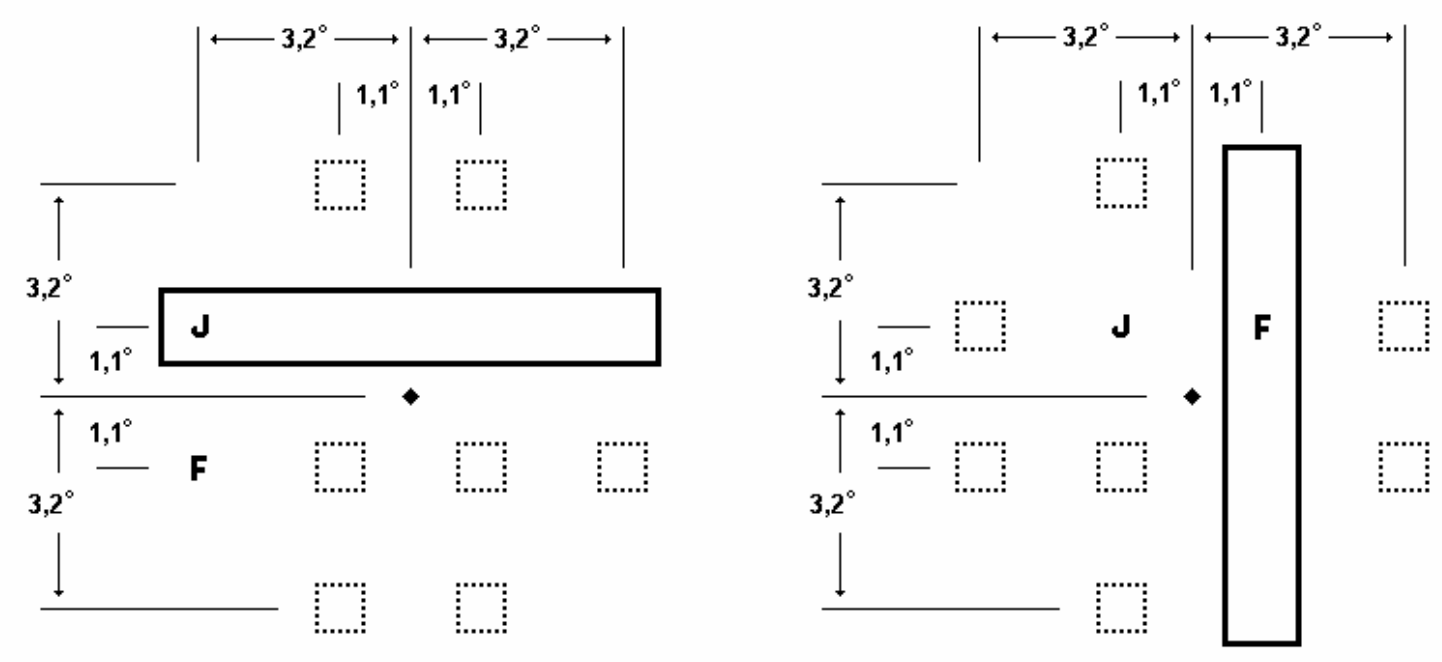

Figura 9. Estímulos utilizados no experimento 3. As duas letras ( $\mathrm{F} \mathrm{e} \mathrm{J)} \mathrm{e} \mathrm{a} \mathrm{moldura}$ (retângulo) exemplificam a distância e as posições em que as letras foram apresentadas dentro e fora da moldura. A moldura poderia aparecer na orientação horizontal (lado esquerdo da figura 9) ou na orientação vertical (lado direito da figura 9), respectivamente acima ou abaixo, a direita ou a esquerda do ponto de fixação. Os quadrados pontilhados representam as localizações em que as duas letras foram apresentadas.

\section{Procedimento}

A tarefa do participante foi igual a do experimento $1 \mathrm{~A}$, ou seja, julgar qual letra foi apresentada primeiro e as respostas foram realizadas no teclado do computador.

A seqüência dos eventos em cada prova foi semelhante à seqüência dos eventos das provas do experimento 2 com uma única alteração. O intervalo de exposição da moldura (IEM) variou em 60, 110, 210 e 409 ms, antes da apresentação da primeira letra.

Em $50 \%$ das provas "F" apareceu primeiro (25\% dentro e $25 \%$ fora da moldura) e em $50 \%$ das provas "J" apareceu primeiro (25\% dentro e $25 \%$ fora da 
moldura). A primeira letra apresentada ( $F$ ou J), a localização da primeira letra (dentro ou fora da moldura), o IEM (60, 110, 210 e 409 ms) e o SOA (20, 30, 60, 100 e $200 \mathrm{~ms}$ ) foram aleatoriamente apresentados em 20 provas treino e 640 provas teste com oito repetições para cada fator.

$\underline{\text { Análise }}$

Respostas muito lentas e provas treino foram excluídas de novas análises. As respostas a serem excluídas foram escolhidas empregando o cálculo de desvio adotado nos experimentos anteriores (ver análise experimento 1a).

Os PSSs das condições dentro e fora da moldura de cada intervalo de tempo (60, 110, 210 e $409 \mathrm{~ms})$ em que a moldura permaneceu exposta antes da apresentação da primeira letra foram calculados seguindo o procedimento de análise do experimento $1 \mathrm{~A}$. $\mathrm{O}$ efeito de entrada prioritária foi obtido a partir da diferença entre os PSSs das condições dentro e fora da moldura para cada intervalo de exposição da moldura. A AP de cada intervalo foi obtida pela metade da diferença entre a letra apresentada fora e dentro da moldura.

Os PSSs foram submetidos a uma análise de variância $(p>0,05)$ para as medidas repetidas dos seguintes fatores experimentais: posição da primeira letra (dentro, fora da moldura) e IEM (60, 110, 210 e $409 \mathrm{~ms})$. Outra ANOVA das medidas repetidas das APs dos quatro IEM foi realizada.

\section{Resultados}

Uma média de $5,1 \%$ das provas foi excluída de novas análises devido a repostas muito atrasadas e um participante não foi incluído nas análises posteriores devido a PSSs muito fora da média (quatro desvios padrão da média). 
A análise dos PSSs (figura 10) mostrou que a apresentação dos estímulos dentro (-29 ms) e fora $(25 \mathrm{~ms})$ da moldura foram fontes significativas de variância $F(1,13)=126,82 ; p<0,0001$, o tempo de exposição da moldura antes da apresentação da primeira letra produziu um efeito significativo sobre os PSSs $F(3,39)=4,22$; $p<0,011$, e ocorreu uma interação significativa entre os fatores $F(3,39)=4,02$; $p<0,014$. A análise do teste post - hoc (Newman - Keuls, $p<0,05)$ mostrou que a média dos PSSs das letras apresentadas primeiro dentro e fora da moldura para o IEM de $60 \mathrm{~ms}$ (PSS= -5ms) foi diferente do IEM de $110 \mathrm{~ms}$ (PSS=2ms) e este último foi diferente dos IEM de 210 e 409 ms (PSS=-2ms). Outro teste post - hoc para os dois fatores revelou que a curta exposição da moldura por $60 \mathrm{~ms}$ produziu uma tendência de o PSS ser mais amplo (-36 ms) do que o PSS (-24ms) do IEM de 409 ms para a condição em que a letra foi apresentada primeiro dentro da moldura. $\mathrm{Na}$ condição fora, essa diferença ocorreu entre o IEM de 110ms (PSS=33ms) e o IEM de $409 \mathrm{~ms}$ (PSS=19ms).

A média das APs para cada um dos quatro intervalos de exposição da moldura é mostrada na figura 11. A análise estatística revelou um efeito entre as quatro APs $(F(3,39)=4,02 ; p<, 0138)$. O teste post - hoc (Newman - Keuls, $p<0,05)$ mostrou que as acelerações perceptuais são maiores (31 e 31 ms) nos intervalos curtos de 60 e $110 \mathrm{~ms}$, e menores (21 ms) no intervalo mais longo de $409 \mathrm{~ms}$. A AP geral foi estimada em 27 ms. 


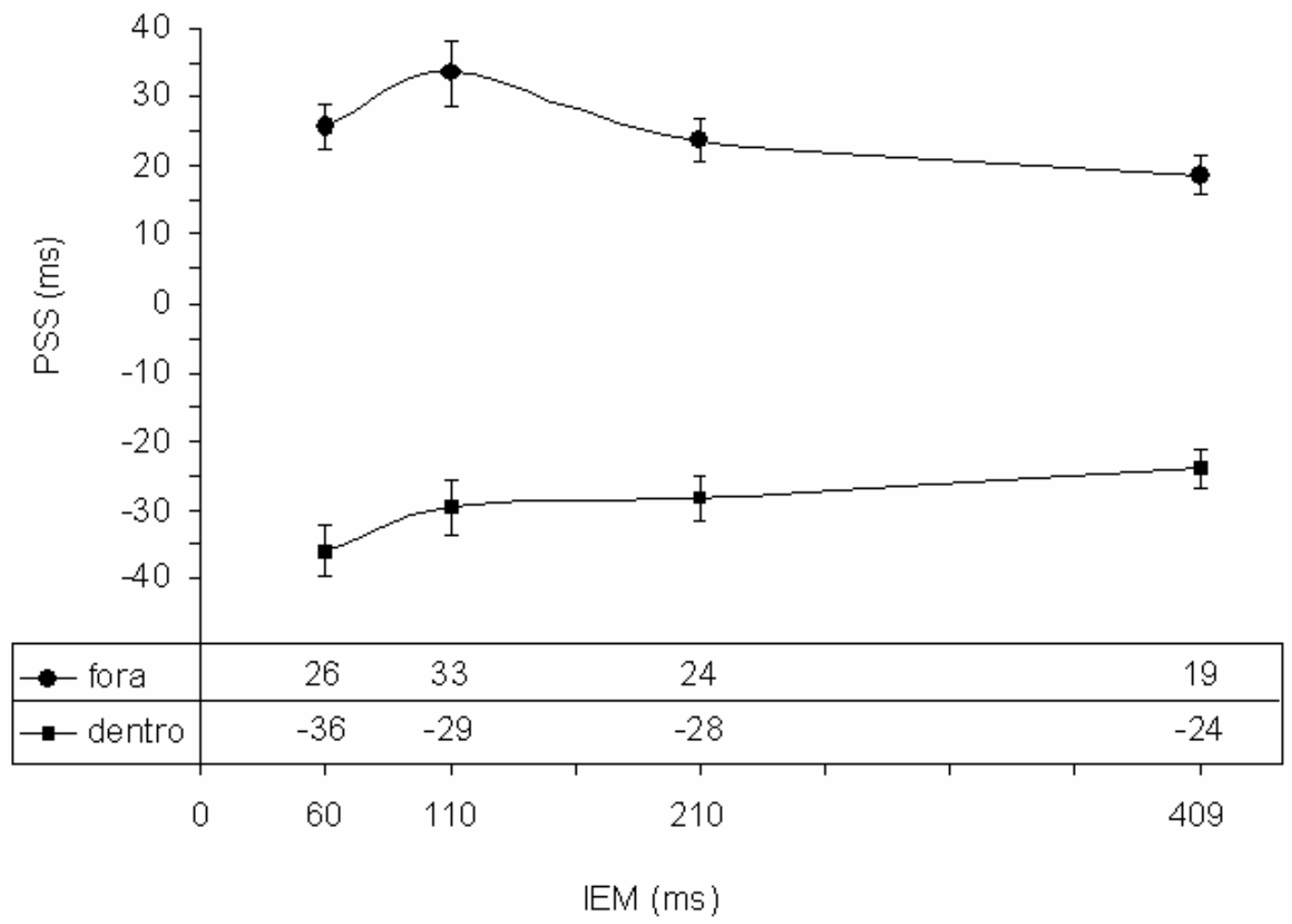

Figura 10. Pontos de simultaneidade subjetiva (PSSs) das letras apresentadas primeiro dentro e fora de uma moldura em função do intervalo de exposição da moldura (IEM= 60, 110, 210 e $409 \mathrm{~ms}$ ). Os valores positivos representam os PSSs da condição em que as letras foram apresentadas fora da moldura e os valores negativos da condição dentro. 


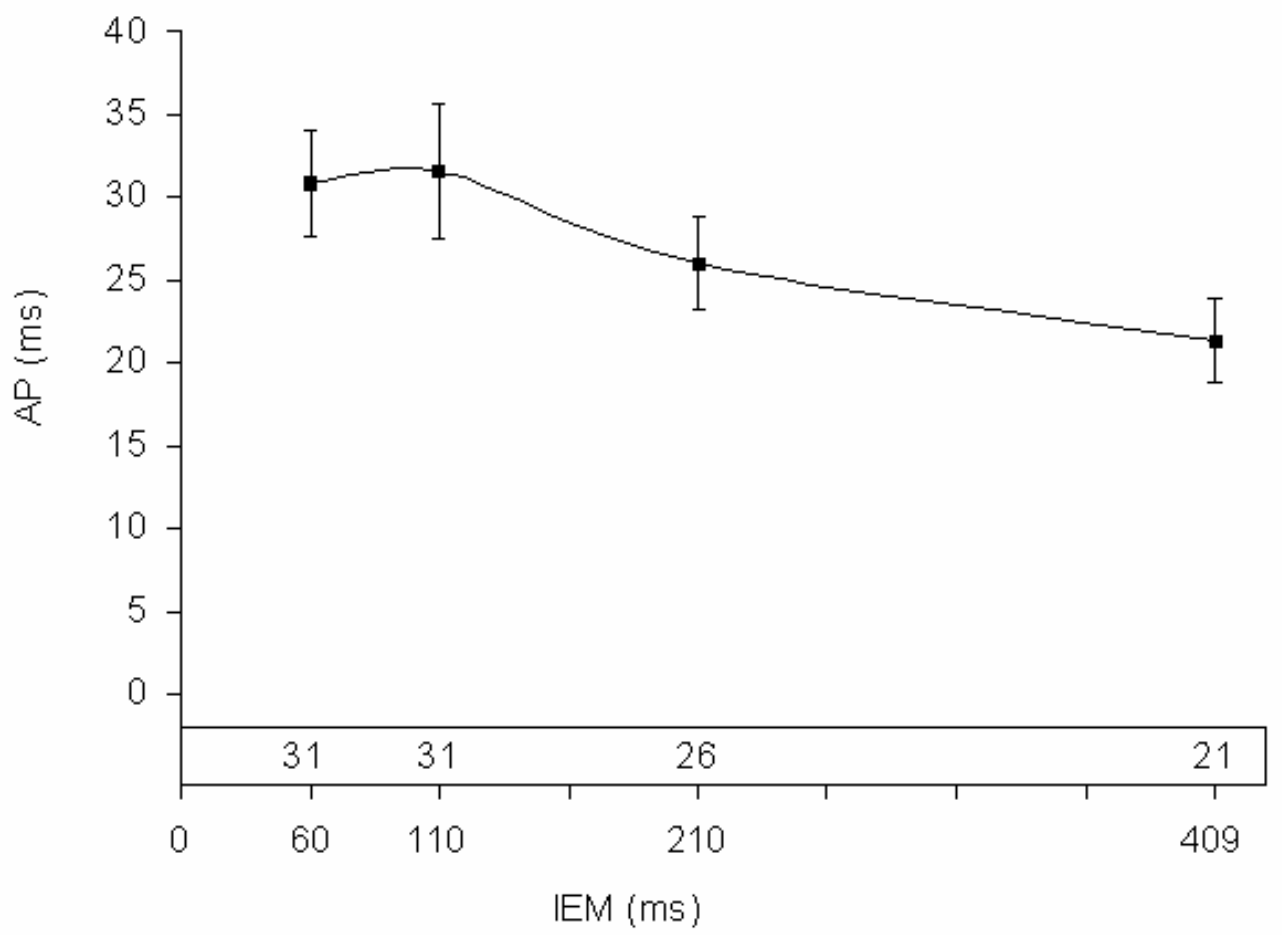

Figura 11. Relativa aceleração perceptual (AP) das letras apresentadas dentro da moldura em relação às letras apresentadas fora em função de cada intervalo de exposição da moldura (IEM=60, 110, 210 e $409 \mathrm{~ms}$ ). As barras verticais indicam o erro padrão da estimativa.

\section{Discussão}

Da mesma maneira que nos experimentos anteriores, a apresentação da moldura afetou significativamente a percepção de ordem temporal dos participantes, sendo demonstrada na diferença entre os PSS da condição dentro e fora. A média dos PSSs das condições dentro e fora de cada IEM demonstra que, no período mais curto de exposição da moldura (IEM=60ms), existiu um pequeno ganho da letra apresentada primeiro dentro da moldura, enquanto no período de exposição de $110 \mathrm{~ms}$, o custo associado a letra apresentada fora foi mais relevante na percepção de ordem temporal dos participantes do que o ganho no mesmo período de tempo 
(figura 10). Nos intervalos mais longos (IEM= 210 e 409 ms) essa diferença não ocorreu, mostrando que o julgamento dos participantes foi mais influenciado no intervalo entre 60 e 110 ms de exposição da moldura. O efeito proporcionado pela apresentação da moldura em função dos quatro IEM é bem evidente ao se observar a vantagem relativa entre dentro e fora, que demonstra maior AP por volta de $85 \mathrm{~ms}$ de exposição da moldura, caindo à medida que este tempo aumentou (figura 11).

Os resultados sugerem que a atenção seguiu um padrão tipicamente exógeno de distribuição, também encontrado em outros estudos (CHEAL; LYON, 1991; MÜLLER; RABBITT, 1989; NAKAYAMA; MACKEBEN, 1989). Schneider e Bavelier (2003) verificaram uma distribuição do efeito de aceleração para a JOT muito semelhante aos resultados deste experimento, com um pico de aceleração por volta dos 40ms de exposição da moldura. Stelmach e Herdman (1991) apresentaram uma dica exógena por 250 ms antes de desaparecer e observaram um deslocamento máximo dos PSS por volta de 50 ms para o mesmo tipo de julgamento. Shore et al. (2001a) usaram um período de dica de 60ms e encontraram um deslocamento do PSS de aproximadamente $74 \mathrm{~ms}$.

Schneider e Bavelier (2003) argumentam que a existência de um efeito de aceleração, necessariamente não valida a hipótese de entrada prioritária. Existe a possibilidade desta aceleração também ser causada por uma facilitação sensorial e não pela atenção. Mesmo considerando que fatores sensoriais estejam presentes, trabalhos têm demonstrado um aumento na taxa de processamento da informação, quando uma região delimitada do campo visual é indicada de maneira endógena, sugerindo a ativação top-down dos recursos atentivos para a região indicada. Por exemplo, Panagopoulos et al. (2004) utilizando figuras geométricas muito semelhantes às molduras usadas neste estudo, mostraram um deslocamento 
endógeno da atenção para a região delimitada pelas molduras. Stelmach e Herdman (1991) utilizando o paradigma da JOT encontraram um efeito por volta de 43ms para dicas endógenas e, Shore et al. (2001a) um efeito de entrada prioritária de 30ms com o mesmo tipo de dica. Embora Schneider e Bavelier (2003) não tenham encontrado o mesmo efeito utilizando dicas endógenas, os resultados relatados são fortes indícios de que a alteração na percepção de ordem temporal foi em grade parte produzida por um processo atentivo.

Além disso, o fato do efeito de aceleração perceptual ocorrer em um IEM de 100ms é relatado a favor do ajuste automático do foco atentivo ao tamanho da região delimitada (BENSO et al., 1998; MARINGELLI; UMILTÀ, 1998; TURATTO et al., 2000). Como a moldura permaneceu na tela durante a apresentação das letras, é provável que o sistema visual tenha utilizado a região emoldurada como âncora para ajustar o foco atentivo à forma da moldura (GALERA et al., 2005; PANAGOPOULOS et al., 2004).

Embora os movimentos oculares não tenham sido monitorados neste experimento e nos dois primeiros, é pouco provável que esse tipo de variável tenha mudado significativamente os resultados obtidos. Os efeitos atentivos mais significativos para a moldura foram observados em um período de dica muito curto (100ms). Isso sugere que os participantes não moveram os seus olhos para um local indicado antes que o alvo tivesse aparecido. Por exemplo, Crawford e Muller (1992) encontraram movimentos oculares usando dicas exógenas apenas acima de 200 ms. Os resultados do experimento 3 também sugerem que os participantes não direcionaram o olhar para a moldura nos intervalos mais longos, por que ocorreu uma queda na magnitude dos PSSs e das APs com o aumento do IEM. Caso os participantes tivessem direcionado o olhar para a moldura, essa queda não deveria 
ter ocorrido. Mesmo considerando a ocorrência do movimento dos olhos para a moldura nos IEM mais longos utilizados neste experimento, Stelmach e Herdman (1991) monitoram os movimentos dos olhos dos seus participantes, em um de seus experimentos com a JOT, e não encontraram diferença quando foram excluídas provas com movimentos oculares. Nakayama e Mackeben (1989) utilizando uma tarefa de discriminação, também encontraram uma queda no desempenho dos participantes conforme o aumento do tempo de exposição da região indicada, assim como no experimento 3 deste estudo. Verificaram a mesma tendência quando movimentos oculares foram monitorados, não alterando a conclusão de que por volta de $100 \mathrm{~ms}$ ocorre um efeito transitório da atenção, com uma queda para intervalos acima de $400 \mathrm{~ms}$. 

3. Discussão Geral 

O princípio de que o aparecimento abrupto de um objeto deve capturar a atenção de maneira automática (REMINGTON; JOHNSTON; YANTIS, 1992; YANTIS; JONIDES, 1984), assim como, evidências de que figuras com formas geométricas específicas podem interferir na distribuição dos recursos atentivos (CASTIELLO; UMILTÀ, 1990; EGLY; HOMA, 1984; GALERA et al., 2005; PANAGOPOULOS et al., 2004), nos levou a investigar se a apresentação de uma moldura, não relatada para a tarefa, interferiria na percepção de ordem temporal dos participantes. Nossa suposição foi a de que a apresentação da figura com bordas definidas poderia iniciar a captura automática da atenção. A apresentação de um dos estímulos relevantes para a tarefa dentro da área emoldurada, permitiria seu processamento privilegiado, de maneira análoga ao que acontece com estímulos apresentados dentro de objetos e posições espaciais (por exemplo, CASTIELLO; UMILTÀ, 1990; POSNER et al., 1980).

Os resultados dos três experimentos demonstraram que a apresentação de uma das letras alvo dentro e a outra fora da forma geométrica, alterou a percepção de ordem temporal dos participantes. Ocorreu uma vantagem em todas as condições experimentais para a letra apresentada dentro da moldura, em relação à letra apresentada fora. Os resultados são coerentes com outros trabalhos que têm investigado o efeito de entrada prioritária visual (HIKOSAKA; MIYAUCHI; SHIMIJO, 1993; SHORE et al., 2001a; STELMACH; HERDMAN, 1991), sugerindo que o efeito observado pode ser resultado da maior concentração de recursos atentivos dentro da região emoldurada.

A possibilidade da alteração na percepção de ordem temporal ser explicada por outros processos que não o sensorial, mas sim pela adoção de um critério para a realização da resposta, levou a aplicação de um controle simples para estimar o 
viés. Isso foi feito no experimento 1B com a introdução de uma segunda tarefa JOT, que solicitou aos participantes o julgamento "qual a segunda letra apresentada?". Um estímulo barra também foi apresentado em um terço das provas, simulando uma situação sem a moldura, com distribuição igual dos recursos atentivos para os dois estímulos relevantes para a tarefa. $\mathrm{O}$ efeito encontrado nos dois tipos de julgamento sugeriu um viés de resposta baixo e o desempenho dos participantes na situação sem a moldura indicou que, quando uma das letras não foi delimitada pela moldura, os recursos atentivos foram distribuídos livremente ao redor da barra, não alterando a percepção de ordem temporal dos participantes. Os resultados reforçam a idéia de que os recursos atentivos podem ser mais concentrados dentro das bordas da região delimitada pela moldura, respeitando os limites das margens dessa região (CASTIELLO; UMILTÀ, 1990; CAVE; BICHOT, 1999; GALERA et al., 2005; PANAGOPOULOS et al., 2004).

Os resultados do experimento $1 \mathrm{~A}$ também sugerem que a distribuição dos recursos atentivos pode ser mais concentrada sobre o meridiano horizontal. A aceleração perceptual maior das letras apresentadas dentro da moldura horizontal, estaria de acordo com os dados de estudos que encontraram uma concentração atentiva maior quando regiões horizontais foram indicadas (CARRASCO; MCELREE; GIORDANO, 2002; GALERA, et al., 2005 ; PANAGOPOULOS et al., 2004; SANDERS; BRÜCK, 1991).

A maior vantagem temporal para a letra apresentada na moldura horizontal, em relação à moldura vertical, não foi observada no experimento 1B. A ausência desse efeito pode ter sido causada pela apresentação da barra em um terço das provas, que aumentou a incerteza sobre a localização espacial das duas letras. A inconsistência desse efeito pode ser resultado de uma mudança do sistema de 
deslocamento exógeno da atenção para responder seletivamente apenas às propriedades dos dois estímulos relevantes para a tarefa (FOLK; REMINGTON; JOHNSTON, 1992). Isso pode ter restringido a distribuição da atenção para a região ao redor das duas letras, e não ao longo de toda a moldura horizontal ou vertical. Essa hipótese em parte é contrária a idéia de que os recursos atentivos foram distribuídos ao longo de toda a moldura, mas mesmo que o sistema visual tenha se "ajustado" apenas a uma pequena porção ao redor das duas letras, o efeito entre dentro e fora permaneceu. Portanto, as bordas da moldura ainda parecem ter influenciado a percepção de ordem temporal dos participantes. Resultados semelhantes foram encontrados recentemente em nosso laboratório retirando-se partes de uma moldura vertical apresentada sempre ao centro do campo visual com flankers próximos as suas bordas e ao alvo (CAVALET et al., 2006). Os dados mostram que as bordas da moldura, entre o alvo e os flankers, influenciaram o efeito de incompatibilidade, interferindo na seleção da informação relevante para a tarefa.

Outra evidência de uma distribuição desigual dos recursos atentivos foi encontrada no experimento 2. A manipulação da distância entre as duas letras demonstrou maior facilidade na percepção das letras apresentadas próximas do que distantes uma da outra. Isso pode ser interpretado como mais um indício de que os recursos da atenção foram deslocados para o interior da moldura, produzindo um efeito tipicamente espacial de distribuição atentiva fora das suas bordas quando a distância entre as duas letras foi manipulada (ERIKSEN; YEH, 1985; LABERGE, 1983, LABERGE; BROWN, 1989; POSNER et al., 1980; ZIMBA; HUGHES 1987).

O julgamento de ordem temporal dos participantes também foi alterado quando o tempo de exposição da moldura foi manipulado em um intervalo variável entre 60 e 409 ms. Os resultados indicam que a magnitude do efeito produzido pela 
moldura foi maior entre 60 e 100 ms, atingindo um pico por volta de 85 ms de exposição da moldura. Esse efeito diminuiu quando a moldura foi exposta em intervalos mais longos. Os resultados sugerem que os recursos atentivos foram capturados de maneira automática pela figura geométrica. A queda do efeito conforme o aumento do tempo de exposição da moldura, também indica que após a ativação inicial dos recursos atentivos, a concentração de atenção dentro da moldura pode ter diminuído como resultado da alteração do sistema visual para um controle mais voluntário da distribuição dos recursos atentivos (CHEAL; LYON, 1991; MÜLLER; RABBITT, 1989; NAKAYAMA; MACKEBEN, 1989).

Os resultados dos três experimentos parecem concordar com a idéia de que estímulos apresentados dentro de objetos atendidos são processados com certa vantagem em relação a objetos não atendidos (DUNCAN, 1984). No entanto, o fato de nos três experimentos os estímulos relevantes para a tarefa e a moldura serem apresentados em diferentes localizações, não permite dizer se os efeitos obtidos foram resultados de uma seleção baseada apenas no objeto. Assim, nossos resultados parecem concordar mais com estudos recentes que têm sugerido a seleção da informação visual combinada, ou seja, integrando a informação espacial com as características dos objetos, quando um alvo é apresentado (BROWN; BREITMEYER; LEIGHTY; DENNEY, 2006; EGLY; DRIVER; RAFAL, 1994; KRAMER; JACOBSON, 1991; LAVIE; DRIVER, 1996; VECERA; FARAH, 1994).

Dada a importância da localização espacial e a importância do próprio objeto na seleção da informação, nós temos trabalhado com a idéia de que a atenção pode se espalhar por regiões delimitadas do campo visual, ajustando-se ao tamanho e a forma dos objetos apresentados (CAVALET et al., 2006; GALERA et al., 2005 ; PANAGOPOULOS et al., 2004). Os resultados obtidos nestes três experimentos 
parecem estar de acordo com essa suposição, demonstrando que a apresentação de uma figura com forma geométrica simples, pode produzir uma redistribuição automática dos recursos atentivos, ocorrendo maior concentração desses recursos dentro do que fora da região delimitada. Estudos comportamentais que venham a manipular o tamanho e os limites da região emoldura, podem fornecer novas descobertas sobre os mecanismos da atenção visual. 



\section{REFERÊNCIAS BIBLIOGRÁFICAS}

ALLIK, J. \& KREEGIPUU, K. (1998). Multiple visual latency. Psychological Science, $\underline{9}, 135-138$.

BAYLIS, G.C., \& DRIVER, J. (1993). Visual attention and objects: evidence for hierarchical coding of location. Journal of Experimental Psychology: Human Perception \& Performance, $19,451-470$.

BENSO, F., TURATTO, M., MASCETTI, G.G, \& UMILTÀ, C. (1998). The time course of attention focusing. European Journal of Cognitive Psychology, 10, 373-388.

BICHOT, N.P., CAVE, K.R., \& PASHLER, H. (1999). Visual selection mediated by location: Feature-based selection of noncontiguous locations. Perception \& Psychophysics, 61, 403-423.

BROADBENT, D.(1958). Perception and communication. Pergamon Press, London

BROWN, J.M., BREITMEYER, B.G., LEIGHTY, K.A., \& DENNEY, H.I. (2006). The path of visual attention. Acta Psychologica, 121, 199-209.

CARRASCO, M., MCELREE, B., \& GIORDANO, A.M. (2002). Covert attention speeds information accrual more along the vertical than the horizontal meridian. In: Vision Sciences Society, 452-B4.15, Sarasota.

CASERTA, G., CAVAllet, M., GALERA, C., \& VON GRÜNAU, M. W. (2005). Um estudo de viés de resposta em tarefa de julgamento de ordem temporal. $\underline{X X}$ Reunião Anual da Federação de Sociedade de Biologia Experimental - FeSBE.

CASTIELLO, U., \& UMILTÀ, C. (1990). Size of the attentional focus and efficiency of processing. Acta Psychologica, 73, 195-209.

CAVALLET, M., RONDINONI, C., GALERA, C., \& VON GRÜNAU, M. W. (2006) Efeito de dicas não-preditivas na presença de flanqueadores durante uma tarefa de identificação visual. In: I Congresso Interno do Programa de Pós-Graduação em Psicobiologia.

CAVE, K.R., \& BICHOT, N.P. (1999). Visuospatial attention: beyond a spotlight model. Psychonomic Bulletin \& Review, 6, 204-223.

CHEAL, M., \& LYON, D.R. (1991). Central and peripheral precuing of forced-choice discrimination. Quarterly Journal of Experimental Psychology, 43, 859-880. 
COLE, G., GELLATLY, A., \& BLURTON, A. (2001). Effect of Object on the Distribution of Visual Attention. Journal of Experimental Psychology: Human Perception \& Performance, 27, 1356-1368.

CRAWFORD, T.J., \& MULLER, H.J. (1992). Spatial and temporal effects of spatial attention on human saccadic eye movements. Vision Research, 32, 293-304.

DUNCAN, J. (1984). Selective attention and the organization of visual information. Journal of Experimental Psychology: General, 113, 501-517.

EGETH, H.E., \& YANTIS, S. (1997). Visual attention: control, representation, and time course. Annual Review of Psychology, 48, 269-297.

EGLY, R., DRIVER, J., \& RAFAL, R.D. (1994). Shifting visual attention between objects and locations: evidence from normal and parietal lesion subjects. Journal of Experimental Psychology: General, 123, 161-177.

EGLY, R., \& HOMA, D. (1984). Sensitization of the visual field. Journal of Experimental Psychology: Human Perception \& Performance, 10, 778-793.

ERIKSEN, C.W., \& ST. JAMES, J.D. (1986). Visual attention within and around the field of focal attention: A zoom lens model. Perception \& Psychophysics, 40, 225240.

ERIKSEN, C.W., \& YEH, Y. (1985). Allocation of attention in the visual field. Journal of Experimental Psychology: Human Perception \& Performance, 11, 583-597.

FOLK, C.L., REMINGTON, R.W., \& JOHNSTON, J.C. (1992). Involuntary covert orienting is contingent on attentional control setting. Journal of Experimental Psychology: Human Perception \& Performance, 18, 1030-1044.

GALERA, C., VON GRÜNAU, M., \& PANAGOPOULOS, A. (2005). Automatic focusing of attention on object size and shape. Psicológica, 26, 147-160.

GIBSON, B.S. (1994). Visual attention and objects: one versus two or convex versus concave? Journal of Experimental Psychology: Human Perception \& Performance, 20, 203-207.

HADDAD, JR.H., CARREIRO, L.R.R., \& BALDO, M.V.C. (2002). Modulation of the perception of temporal order by attentional and pré-attentional factors. Brazilian Journal of Medical and Biological Research, 35, 979-983.

HADDAD, JR.H., KLEIN, S., \& BALDO, M.C.V. (1999). The contribution of attentional and pre-attentional mechanisms to the perception of temporal order. In: Taddei- 
Ferretti, C., \& Musio, C. (Editor), Neuronal Bases and Psychological Aspects of Consciousness. World Scientific, Singapore.

HIKOSAKA, O., MIYAUCHI, S., \& SHIMOJO, S. (1993). Focal visual attention produces illusory temporal order and motion sensation. Vision Research, 33, 12191240.

JASKOWSKI, P. (1993). Selective attention and temporal-order judgment. Perception, 22, 681-689.

JONIDES, J. (1983). Further toward a model of the mind's eye's movement. Bulletin of the Psychonomic Society, 21, 247-250.

JUOLA, J.F., BOUWHUIS, D.G., COOPER, E.E., \& WARNER, C.B. (1991). Control of attention around the fovea. Journal of Experimental Psychology: Human Perception \& Performance, 17, $125-141$.

JUOLA, J.F., CROUCH, T., \& COCKLIN, T. (1987). Voluntary control of attention near the fovea. Acta Psychologica, 63, 207-217.

KAHNEMAN, D., TREISMAN, A., \& GIBBS, B. (1992). The reviewing of object files: Object-specific integration of information. Cognitive Psychology, 24, 175-219.

KRAMER, A. F., \& JACOBSON, A. (1991). Perceptual organization and focused attention: The role of objects and proximity in visual processing. Perception \& Psychophysics, 50, 267-284.

LABERGE, D. (1983). Spatial extent of attention to letters and words. Journal of Experimental Psychology: Human Perception \& Performance, 9, 371-379.

LABERGE, D., \& BROWN, V. (1989). Theory of attentional operation in shape identification. Psychological Review, 96, 101-124.

LAVIE, N., \& DRIVER, J. (1996). On the spatial extent of attention in object-based visual selection. Perception \& Psychophysics, 58, 1238-1251.

MARINGELLI, F., \& UMILTÀ, C. (1998). The control of the attentional focus. European Journal of Cognitive Psychology, 10, 225-246.

MÜLLER, M.M., \& HÜBNER, R. (2002). Can the spotlight of attention be shaped like a doughnut? Psychological Science, 13, 119-124. 
MÜLLER, H. J., \& RABBITT, P. M. A. (1989). Reflexive and voluntary orienting of visual attention: time course of activation and resistance to interruption. Journal of Experimental Psychology: Human Perception \& Performance, 15, 315-330.

NAKAYAMA, K., \& MACKEBEN, M. (1989). Sustained and transient components of focal visual attention. Vision Research, 29, 1631-1647.

PANAGOPOULOS, A., VON GRÜNAU, M.W., \& GALERA, C. (2004). Attentive mechanisms in visual search. Spatial Vision, 17, 353-371.

PARK, REY \& SCHLAG (2003). Spatial localization precedes temporal determination in visual perception. Vision Research, 43, 1667-1674.

PASHLER, H., JOHNSTON, J. C., \& RUTHRUFF, E. (2001). Attention and performance. Annual Review of Psychology, 52, 629-651.

POSNER, M. I. (1980). Orienting of attention. Quarterly Journal of Experimental Psychology, 32, 3-25.

POSNER, M. I., SNYDER, C. R. R., \& DAVIDSON, B. J. (1980). Attention and the detection of signals. Journal of Experimental Psychology: General, 109, 160-174.

REMINGTON, R.W., JOHNSTON, J.C., \& YANTIS, S. (1992). Involuntary attention capture by abrupt onsets. Perception \& Psychophysics, 51, 279-290.

SANDERS, A.F., \& BRÜCK, R. (1991). The effect of presentation time on the size of the visual lobe. Bulletin of the Psychonomic Society, 29, 206-208.

SCHARLAU, I. (2004a). The spatial distribution of attention in perceptual latency priming. The Quarterly Journal of Experimental Psychology, 57, 1411-1436.

SCHARLAU, I. (2004b). Evidence for split foci of attention in a priming paradigm. Perception \& Psychophysics, 66, 988-1002.

SCHNEIDER, K. A., \& BAVELIER, D. (2003). Components of visual prior entry. Cognitive Psychology, 47, 333-366.

SCHNEIDER, W., ESCHMAN, A., \& ZUCCOLOTTO, A. (2002). E-Prime User's Guide. Pittsburgh: Psychology Software Tools Inc.

SHOMENSTEIN, S. \& YANTIS, S. (2002). Object-based attention: sensory modulation or priority setting? Perception \& Psychophysics, 64, 41-51. 
SHORE, D.I., SPENCE, C., \& KLEIN, R.M. (2001a). Visual prior entry. Psychological Science, 12, 205-212.

SPENCE, C., SHORE, D.I., \& KLEIN, R.M. (2001b). Multisensory prior entry. Journal of Experimental Psychology: General, 130, 799-832.

STELMACH, L.B., \& HERDMAN, C.M. (1991). Directed attention and perception of temporal order. Journal of Experimental Psychology: Human Perception and Performance, $17,539-550$.

STERNBERG, S., \& KNOLL, R.L. (1973). The perception of temporal order: fundamental issues and a general model. Em: Kornblum, S. (Editor), Attention and Performance IV. Academic Press, New York, NY, USA, 629-685.

TITCHENER, E.B. (1908). Lectures on the elementary psychology of feeling and attention. New York: Macmillan.

TURATTO M., BENSO F., FACOETTI A., GALFANO G., MASCETTI G.G., \& UMILTÀ C. (2000). Automatic and voluntary focusing of attention. Perception \& Psychophysics, 62, 935-952.

VECERA, S.P., \& FARAH, M.J. (1994). Does visual attention selection objects or locations? Journal of Experimental Psychology: General, 123, 146-160.

YANTIS, S., \& JONIDES, J. (1984). Abrupt visual onset and selective attention: Evidence from visual search. Journal of Experimental Psychology: Human Perception \& Performance, 10, 601-621.

YANTIS, S., \& JONIDES, J. (1990). Abrupt visual onsets and selective attention: Voluntary versus automatic allocation. Journal of Experimental Psychology: Human Perception \& Performance, 16, 121-134.

YANTIS, S., \& JONIDES, J. (1996). Attentional capture by abrupt onsets: new perceptual objects or visual masking? Journal of Experimental Psychology: Human Perception \& Performance, 22, 1505-1513.

ZAMPINI, M., SHORE, D.I., \& SPENCE, C. (2005). Audiovisual prior entry. Neuroscience Letters, 381, 217-222.

ZIMBA, L.D., \& HUGHES, H.C. (1987). Distractor-target interactions during directed visual attention. Spatial Vision, 2, 117-149. 



\section{ANEXOS}

1. Tabelas das análises estatísticas

2. Termo de Consentimento do sujeito da Pesquisa

3. Declaração do Comitê de Ética em Pesquisa - CEP 


\section{Experimento $1 \mathrm{~A}$}

\subsection{Análise dos PSSs}

Resultados da Análise de Variância para Medidas Repetidas

\begin{tabular}{|c|c|c|c|c|c|c|}
\hline \multicolumn{7}{|c|}{$\begin{array}{l}\text { Resumo dos efeitos } \\
\text { 1-Posicã }\end{array}$} \\
\hline & gl & QM & $\mathrm{gl}$ & QM & & \\
\hline & Efeito & Efeito & Desvio & Desvio & $\mathrm{F}$ & $p$ \\
\hline 1 & 1 & 49234,98 & 7 & 693,6883 & 70,97566 & 0,0001 \\
\hline 2 & 1 & 137,7758 & 7 & 37,43178 & 3,680718 & 0,0965 \\
\hline 12 & 1 & 877,4175 & 7 & 131,67 & 6,66376 & 0,0364 \\
\hline
\end{tabular}

1

Médias

$\mathrm{F}(1,7)=70,98$;

$p<0,0001$

$\begin{array}{cc} & \text { Var. } \\ 1 & -43 \\ 2 & 35\end{array}$

2

Médias

$F(1,7)=6,66$;

$p<0,0364$

\subsection{Análise das APs}

Resultados do Teste-t

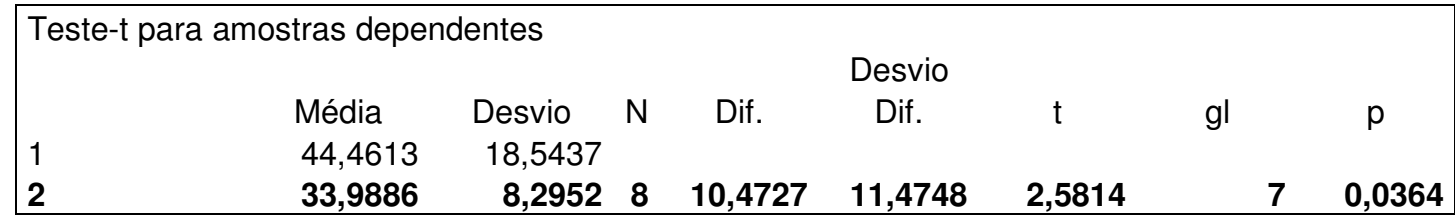

3

Médias

$\mathrm{t}(7)=2,581$;

$t=0,0364$ 


\section{Experimento 1B}

\subsection{Análise dos PSSs}

Resultados da Análise de Variância para Medidas Repetidas

\begin{tabular}{|c|c|c|c|c|c|c|}
\hline \multicolumn{7}{|c|}{$\begin{array}{l}\text { 1-Grupo de julgamento, 2-Tipo de dica, 3-Posição da primeira letra, } \\
\text { 4-Orientação da moldura }\end{array}$} \\
\hline & $\underset{\text { Ffoito }}{\mathrm{gl}}$ & QM & $\mathrm{gl}$ & QM & - & $n$ \\
\hline 1 & 1 & 1492,657 & 16 & 757,1567 & 1,971398 & 0,1794 \\
\hline 2 & 1 & 0,007466 & 16 & 337,4555 & $2,21 \mathrm{E}-05$ & 0,9963 \\
\hline 3 & 1 & 29418,71 & 16 & 2071,006 & 14,20504 & 0,0017 \\
\hline 4 & 1 & 136,8387 & 16 & 453,2463 & 0,301908 & 0,5903 \\
\hline 12 & 1 & 573,045 & 16 & 337,4555 & 1,698135 & 0,2110 \\
\hline 13 & 1 & 237,8774 & 16 & 2071,006 & 0,114861 & 0,7391 \\
\hline 23 & 1 & 65646,91 & 16 & 585,3873 & 112,1427 & $1,23051 \mathrm{E}-08$ \\
\hline 14 & 1 & 641,7275 & 16 & 453,2463 & 1,415847 & 0,2514 \\
\hline 24 & 1 & 136,5916 & 16 & 606,2336 & 0,225312 & 0,6414 \\
\hline 34 & 1 & 1358,775 & 16 & 575,2225 & 2,362172 & 0,1438 \\
\hline 123 & 1 & 680,0452 & 16 & 585,3873 & 1,161701 & 0,2971 \\
\hline 124 & 1 & 252,7764 & 16 & 606,2336 & 0,416962 & 0,5276 \\
\hline 134 & 1 & 959,0166 & 16 & 575,2225 & 1,66721 & 0,2150 \\
\hline 234 & 1 & 2990,466 & 16 & 1343,589 & 2,22573 & 0,1552 \\
\hline 1234 & 1 & 799,9634 & 16 & 1343,589 & 0,595393 & 0,4516 \\
\hline
\end{tabular}

4

Médias

$\mathrm{F}(1,16)=14,21$;

$\mathrm{p}<0,0017$
5

Médias

$F(1,16)=112,14$;

$\mathrm{p}<, 0001$

$\begin{array}{cc} & \text { Var. } \\ 1 & -16 \\ 2 & 13\end{array}$

$\begin{array}{ccc} & & \text { Var. } \\ 1 & 1 & -37 \\ 1 & 2 & 34 \\ 2 & 1 & 6 \\ 2 & 2 & -9\end{array}$




\subsection{Análise das APs}

Resultados da Análise de Variância para Medidas Repetidas

\begin{tabular}{|c|c|c|c|c|c|c|c|}
\hline \begin{tabular}{|l|} 
Res \\
$1-G$ \\
mol
\end{tabular} & $\begin{array}{l}\text { S efeitos } \\
\text { julgamer }\end{array}$ & nto, 2-Tipo c & de dica & & Orientaçã & & \\
\hline & $d f$ & MS & $d f$ & & MS & & \\
\hline & Effect & Effect & Error & & Error & $\mathrm{F}$ & p-level \\
\hline 1 & 1 & 118,9387 & & 16 & 1035,503 & 0,114861 & 0,739 \\
\hline 2 & 1 & 32823,46 & & 16 & 292,6937 & 112,1427 & $1,23051 \mathrm{E}-08$ \\
\hline 3 & 1 & 679,3873 & & 16 & 287,6112 & 2,362172 & 0,1438 \\
\hline 12 & 1 & 340,0226 & & 16 & 292,6937 & 1,161701 & 0,2971 \\
\hline 13 & 1 & 479,5083 & & 16 & 287,6112 & 1,66721 & 0,2150 \\
\hline 23 & 1 & 1495,233 & & 16 & 671,7945 & 2,22573 & 0,1552 \\
\hline 123 & 1 & 399,9817 & & 16 & 671,7945 & 0,595393 & 0,4516 \\
\hline
\end{tabular}

6

Médias

$F(1,16)=112,14$;

$\mathrm{p}<, 0001$

$\begin{array}{cc} & \text { Var. } \\ 1 & 36 \\ 2 & -7\end{array}$


Experimento 2

\subsection{Análise dos PSSs}

Resultados da Análise de Variância para Medidas Repetidas

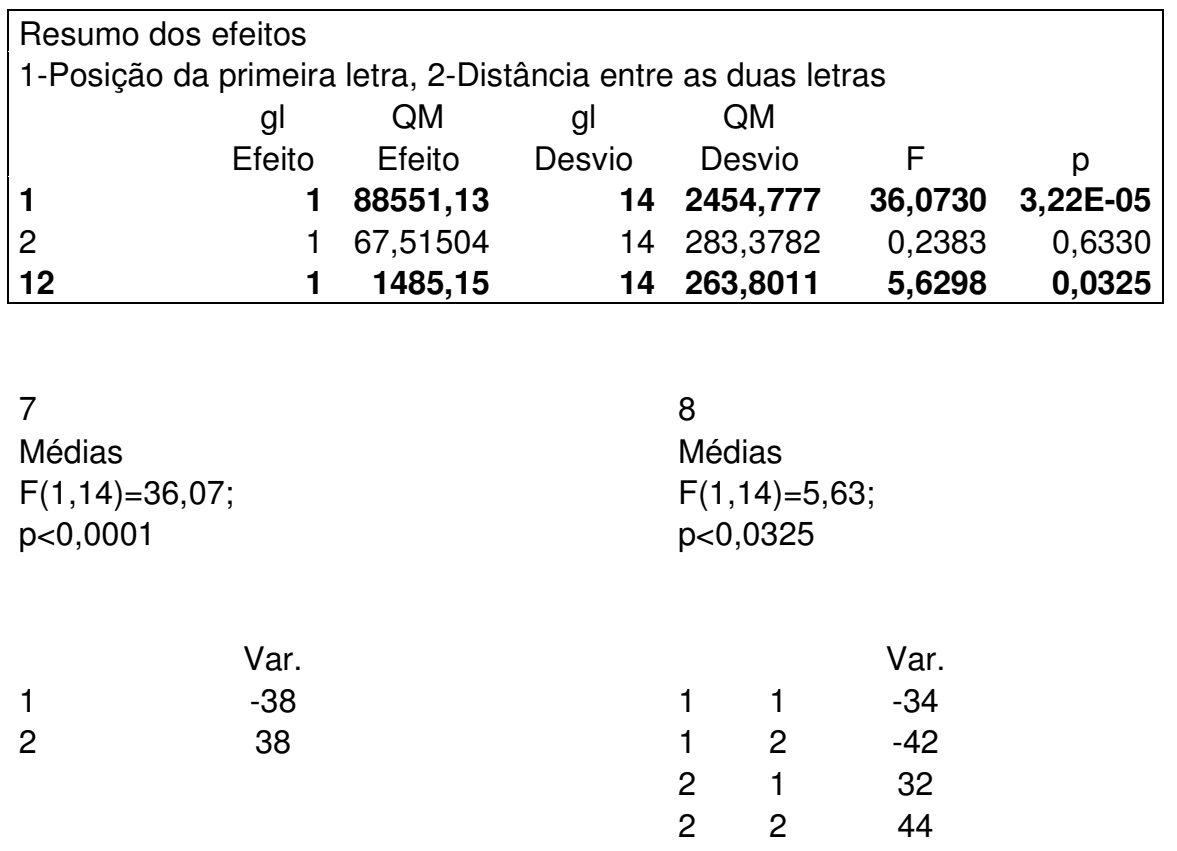

2.2. Análise das APs

Resultados do Teste-t

\begin{tabular}{|c|c|c|c|c|c|c|c|c|}
\hline \multicolumn{9}{|c|}{ Teste-t para amostras dependentes } \\
\hline 1 & $\begin{array}{l}\text { Média } \\
3344163\end{array}$ & $\begin{array}{l}\text { Desvio } \\
2321491\end{array}$ & $\mathrm{~N}$ & Dif. & $\begin{array}{c}\text { Desvio } \\
\text { Dif. }\end{array}$ & $\mathrm{t}$ & $\mathrm{gl}$ & $p$ \\
\hline & & & & - & & - & & \\
\hline 2 & 43,39201 & 28,64187 & 15 & 9,950377 & 16,24195 & 2,372722 & 14 & 0,032 \\
\hline
\end{tabular}

9

Médias

$\mathrm{t}(14)=-2,3727$;

$\mathrm{t}=0,0325$

1

Var.

243 
2.3. Análise dos índices de inclinação das funções

Resultados do Teste-t

\begin{tabular}{|c|c|c|c|c|c|c|c|c|}
\hline \multicolumn{9}{|c|}{ Teste-t para amostras dependentes } \\
\hline 1 & $\begin{array}{l}\text { Média } \\
18,2008\end{array}$ & $\begin{array}{l}\text { Desvio } \\
12,9732\end{array}$ & $\mathrm{~N}$ & Dif. & $\begin{array}{l}\text { Desvio } \\
\text { Dif. }\end{array}$ & $\mathrm{t}$ & gl & $p$ \\
\hline 2 & 31,61378 & 11,77615 & 15 & $13,41297^{-}$ & 16,6292 & 3,123915 & 14 & 0,0075 \\
\hline
\end{tabular}

10

Médias

$\mathrm{t}(14)=-3,1239$;

$\mathrm{t}=0,0075$

1

Var.

2 


\section{Experimento 3}

\subsection{Análise dos PSSs}

Resultados da Análise de Variância para Medidas Repetidas

\begin{tabular}{|c|c|c|c|c|c|c|}
\hline \multicolumn{7}{|c|}{$\begin{array}{l}\text { Resumo dos efeitos } \\
\text { 1-Posição da primeira letra, 2- } \\
\text { IEM }\end{array}$} \\
\hline & gl & QM & $\mathrm{gl}$ & QM & & \\
\hline & Efeito & Efeito & Desvio & Desvio & $\mathrm{F}$ & $p$ \\
\hline 1 & 1 & 83799,453 & 13 & 660,7661 & 126,8217 & 4,46E-08 \\
\hline 2 & 3 & 241,89088 & 39 & 57,335903 & 4,2188 & 0,0112 \\
\hline 12 & 3 & 637,69409 & 39 & 158,51834 & 4,0228 & 0,0138 \\
\hline
\end{tabular}

11

Médias

$F(1,13)=126$,82;

$\mathrm{p}<0,0001$

$\begin{array}{cc} & \text { Var } \\ 1 & -29 \\ 2 & 25\end{array}$

25
12

Médias

$F(3,39)=4,22$;

$p<0,0112$

2

3

4
13

Médias

$F(3,39)=4,02$;

$\mathrm{p}<0,0138$

Var.
-5
2
-2
-3

Var. $-36$

33

24

19 


\subsection{Análise das APs}

Resultados da Análise de Variância para Medidas Repetidas

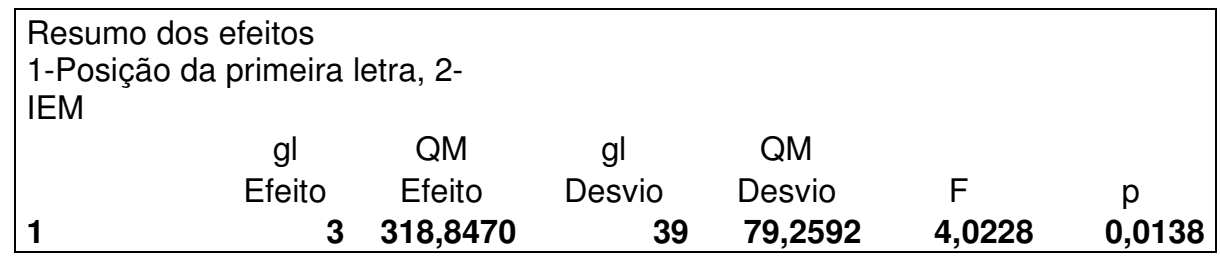

14

Médias

$F(3,39)=4,02$;

$\mathrm{p}<, 0138$

$\begin{array}{ll} & \text { Var. } \\ 1 & 31 \\ 2 & 31 \\ 3 & 26 \\ 4 & 21\end{array}$




\section{Declaração de Consentimento do Voluntário}

Estudo: "Um estudo sobre a distribuição da atenção pelo campo visual usando o julgamento de ordem temporal (JOT)".

1) Eu, abaixo assinado, concordei voluntariamente em participar do estudo acima, sendo que este não oferecerá quaisquer "riscos" a minha saúde física e mental.

2) Recebi instruções detalhadas sobre a natureza e objetivos do estudo e sobre as solicitações que serão feitas.

3) Concordo em ser cooperativo nos procedimentos envolvidos. Minha tarefa será decidir, em cada prova, qual estímulo foi apresentado primeiro no monitor. Minha resposta será dada no teclado do computador e as respostas corretas e erradas, bem como o tempo gasto em cada prova, será registrado para análise.

4) Tenho conhecimento que sou livre para desistir do estudo a qualquer momento, sem necessidade de justificar minha decisão. Caso isso ocorra, comprometome a avisar os pesquisadores o mais rápido possível.

5) Tenho conhecimento que minha participação é sigilosa, isto é, que meu nome não será revelado em qualquer publicação, relatório ou comunicação científica referentes aos resultados da pesquisa. Além disso, eu não tenho o direito de restringir de maneira alguma o uso dos resultados obtidos, desde que eu não seja identificado como sujeito do estudo.

Nome: Data:

Assinatura:

Endereço:

Testemunhado

por:

Assinatura:

Confirmo ter explicado a natureza e objetivos desse estudo ao voluntário acima.

Nome: Assinatura:

Pesquisadores: Mikael Cavallet (mikael@pg.ffclrp.usp.br - 602-4393) e César Galera (orientador - algalera@usp.br-602-4393). 
Of.CEtP/033/2005-19/05/2005

Senhor(a) Pesquisador(a):

Comunicamos a V. Sa. que o trabalho intitulado "A DISTRIBUIÇÃO DA ATENÇÃO NO CAMPO VISUAL USANDO A TAREFA DE JULGAMENTO DA ORDEM TEMPORAL (JOT)" foi analisado pelo Comitê de Ética em Pesquisa da FFCLRP-USP, em sua $42^{a}$ Reunião Ordinária realizada em 16/05/2005, e enquadrado na categoria: APROVADO, de acordo com o Processo CEP-FFCLRP no 180/2005 2005.1.438.59.2

Aproveitamos a oportunidade para apresentar nossos protestos de estima e consideração.

Atenciosamente,

Profa. Dra. Eucla Beatriz Lopes Petean Coordenadora do Comitê de Ética em Pesquisa - FFCLRP-USP

Ilustríssimo Senhor MIKAEL CAVALLET

Aluno do Programa de PG em Psicologia desta FFCLRP

C.C.: Prof. Dr. CÉSAR ALEXIS GALERA

CEP-FFCLRP-USP - Fone: (016) 602-3653 - Fax: (016) 633-5015

Avenida Bandeirantes, 3900 - Bloco A - 14040-901 - Ribeirão Preto - SP - Brasil 